\title{
LA GOBERNANZA DEL SISTEMA DE LAS EXPOSICIONES ECONÓMICAS EN EL REINADO DE ISABEL II (1833-1868)
}

\section{THE GOVERNANCE OF THE SYSTEM OF ECONOMIC EXPOSURES IN THE REIGN OF ISABEL II (1833-1868)}

\author{
José María de Luxán Meléndez \\ Instituto Complutense de Ciencia de la Administración (ICCA) \\ Centro de Estudios Politicos y Constitucionales (CEPC) \\ (jmluxan@cepc.es/jmluxan@ucm.es)
}

\begin{abstract}
Sumario I. INTRODUCCIÓN; II. UNA POLÍTICA PARA LA SOCIEDAD INDUSTRIAL; 2.1. La intensidad de la acción gubernamental; 2.2. El Gobierno durante las exposiciones universales; 2.3. El papel de los gobiernos provinciales; III. LAS EXPOSICIONES DE FOMENTO DE LA SOCIEDAD INDUSTRIAL; 3.1. Tipologia: Estado y Sociedad Civil; 3.2. Los miembros de las comisiones españolas para las exposiciones nacionales y universales; 3.3 Continuidad y renovación; IV. CONCLUSIONES; V. TRABAJOS CITADOS.
\end{abstract}

Resumen: En este trabajo se analizan algunos rasgos institucionales de la política pública para la sociedad industrial. Se estudia la gobernanza de las exposiciones económicas, se pone el foco en el perfil biográfico de los ministros de fomento y de los miembros de las comisiones y jurados españoles en las exposiciones de las décadas centrales del XIX, se describe la intensidad de la acción gubernamental. El sistema de las exposiciones cuenta con un modelo de gobernanza multinivel y multisectorial, unas de iniciativa estatal y otras de la sociedad civil, un ejemplo de colaboración público-privada, en el que, en el ámbito público, destaca un núcleo formado por José Caveda, Alejandro Oliván y Francisco de Luxán.

Abstract: In this paper some institutional features of public policy for industrial society are analyzed. The governance of economic exposures is studied, the focus is on the biographical profile of the development ministers and of the members of the Spanish commissions and juries in the exhibitions of the central decades of the XIX, se describe la intensidad de la acción gubernamental. The exhibition system has a multi-level and multi-sector governance model, some of state initiative and others of civil society, an example of public-private collaboration, in which, in the public sphere, a nucleus formed by José Caveda, Alejandro Oliván and Francisco de Luxán stands out.

Palabras clave: Politicas Públicas. Exposiciones universales. José Caveda. Francisco de Luxán. Alejandro Oliván. Gobernanza. Globalización.

Key Words: Public politics. Universal exhibitions. José Caveda. Francisco de Luxán. Alejandro Oliván. Governance. Globalization. 


\section{INTRODUCCIÓN 1}

La facilidad de las comunicaciones, el nuevo valor que recibirá el tiempo y la percepción de que los ciudadanos lo eran ya del globo, forman parte del discurso de los progresistas españoles sobre el impacto que la tecnología tendrá en los valores de la sociedad del tercio central del XIX, en el que se desarrolló la sociedad industrial, expresión con la que en palabras de Miguel Ángel Quintanilla, se describe la huella de un patrón de producción de bienes materiales en el que las maquinas sustituyeron a las herramientas artesanales, un sistema en el que el vapor reemplazó a la energía tradicional, en el que el trabajo se organizó en factorías, y en el que el capital se independizo del trabajo (Quintanilla, 2005).

En el reinado de Isabel II se desarrolló una política pública de exposiciones primero nacionales y luego universales, una actuación heredera de la administración fernandina, que se inició con la exposición nacional de 1841, que dará paso en la década moderada a la creación del Instituto Industrial y a las exposiciones nacionales de 1845 y 1850, y que a partir del bienio progresista conducirá a la reorganización del Instituto Industrial, a la Exposición agrícola de 1857, al proyecto de la Exposición Hispanoamericana (1859) y a la participación española en las exposiciones universales de Londres $(1851,1862)$ y Paris $(1855$, 1867). Estos hitos señalan que, para promover el fomento y la mejora de la economia, durante la segunda globalización, España al igual que Francia o el Reino Unido transformó una politica de exposiciones nacionales para sumarse al proceso de internacionalización de las exposiciones económicas.

En este trabajo se analiza el proceso de internacionalización de las exposiciones de fomento de la economía en la segunda globalización. Desde el punto de vista de los protagonistas de las exposiciones se pone el foco en los ministros de fomento responsables de la acción gubernamental en esta materia y en los participantes de los comisiones de las exposiciones económicas, para ello se presenta un perfil biográfico de los miembros de los comités y jurados españoles en las exposiciones de las décadas centrales del XIX, y se describe la intensidad de la acción gubernamental en el impulso de una política para la sociedad industrial mediante la celebración de exposiciones industriales y agrícolas.

En este proceso, durante el reinado de Isabel II, la politica para la sociedad industrial, a través de las exposiciones económicas, cuenta un modelo de gobernanza multinivel y multisectorial en el que destaca la decisiva contribución de los progresistas españoles.

La cuestión que se plantea, la gobernanza de las exposiciones, quienes son los protagonistas tiene que ver con dos cuestiones de caracter general. En primer

\footnotetext{
1 Una versión previa de este trabajo con el título La internacionalización de las exposiciones de fomento de la economía en la segunda globalización. La contribución de los progresistas españoles en el reinado de Isabel II, la presente en el seminario sobre la segunda globalización coordinado por Dr. Santiago de Luxán, Dr. Germán Santana y Dr. Miguel Suárez (ULPGC) dentro del XXIV Coloquio de Historia Canario-Americano sobre los procesos de globalización en la historia atlántica que se desarrolló entre los dias 30 de noviembre a 3 de diciembre de 2020, esa ponencia ha sido mejorada con los comentarios críticos de los asistentes, a los que agradezco sus observaciones, aunque sólo soy yo responsable del resultado.
} 
lugar, el binomio Estado-Sociedad en el reinado de Isabel II se articula como Estado Liberal y Sociedad Industrial. Ambos aspectos construyen un proyecto político y económico en el que el relato del progreso, heredero de los liberales de Cádiz, domina la agenda pública, triunfa frente al absolutismo, y no sin dificultades impregna todas las politicas públicas. Una configuración de la administración liberal que pugna entre un modelo de administración participada, en el que el peso de la sociedad civil es significativo y otro de administración burocrática que prima la extensión y la profesionalización del servicio público.

En segundo término, para analizar un proceso que trancurre en las décadas centrales del XIX se emplean las ideas de gobernanza y globalización, dos conceptos estrechamente vinculados que desde la literatura económica sociológica y politológica se extienden en la última década del siglo pasado. El concepto de globalización se presentó conectado a una nueva economía en la que tiempo y espacio construyen una sociedad red, una nueva morfología social que modifica de forma sustancial los procesos de producción, la experiencia, el poder y la cultura. Y aunque la forma en red de la organización social ha existido en otros tiempos y espacios, el nuevo paradigma de la tecnología de la información proporciona la base material para que su expansión cale toda la estructura social (Castells, 2005, pág. 550). Y la idea de gobernanza se ha presentado como un mecanismo alternativo o sustitutorio del gobierno que pone de manifiesto que algunas politicas públicas tienden a convertirse en coproducciones en las que participan las instituciones públicas, otros agentes económicos y sociales y los propios destinatarios o beneficiarios (Vallés, 2020, págs. 427-429).

Por último, el desarrollo de las exposiciones económicas se presenta estrechamente vinculada con un proceso de globalización que acabará por transformar el sentido y el alcance de la universalización de las exposiciones en las que el componente de muestra científico-técnica, de fomento de la industria y de la agricultura, acabará desbordado por la voluntad de mostrar los logros nacionales, de ejercer un liderazgo político, económico y también tecnológico, así como de actuar como palanca de transformación urbana. El éxito acabará midiéndose por el impacto en la opinión pública, por la imagen que se proyecta de cada país, por el número de visitantes y cada vez menos por el interés de los productos, por el intercambio tecnológico o por los procesos de innovación.

José Caveda, Alejandro Oliván y Francisco de Luxán, desde el gobierno, y desde la administración concentran la acción pública en torno a las exposiciones económicas, los tres tuvieron no sólo una posición politica destacada, si no que participaron de forma relevante en las principales instituciones culturales y científico-técnicas. Destaca la transversalidad de una política pública para la sociedad industrial, que tuvo su mayor intensidad, tras la revolución de 1854, primero en el bienio progresista, y luego en el gobierno largo de la Unión Liberal.

Para identificar los rasgos comunes y las diferencias biográficas de los 164 miembros de los comités españoles en las exposiciones nacionales y universales del periodo 1833-1868, los hemos agregado en cuatro grandes categorías (Tabla1).

Participación en exposiciones. Número de veces en las que forman parte de las Junta calificadora de los productos de la industria española o de los comités españoles para exposiciones internacionales. 
Perfil generacional. La cohorte de edad a la que pertenecen, medida por el año de nacimiento, la hemos agrupado en tres generaciones, que hemos denominado generación liberal, generación del progreso y generación demócrata. Para Julián Marías, la idea de generación se extiende al conjunto de los que son coetáneos y tienen además algún contacto vital (Marías, 1949). Una generación, señalaba Ortega, no es un puñado de hombre egregios, ni simplemente una masa: es como un nuevo cuerpo social íntegro (Ortega y Gasset, 1923). El problema de las generaciones es distinguir entre la posición generacional (la edad), la conexión generacional (participación cultural) y la unidad generacional (destino común), tres momentos que determinan la efectividad de la generación que cuenta con un nuevo estilo, con un relato generacional (Mannheim,1922). Para establecer los límites de la generación ${ }^{2}$ que alcanza y desarrolla su madurez política, social, económica e intelectual en las décadas centrales del XIX, se considera como punto de arranque la Revolución Francesa (1789) y como límite superior la Declaración Revolucionaria de Cádiz (1810), con la que las Cortes nacionalizan la soberanía. Este intervalo alcanza una generación nacida en torno al ochocientos que denominamos del progreso que incluye a los nacidos entre 1790 y 1809.

Perfil profesional. En función de las características de las instituciones de la que han formado parte hemos establecido tres perfiles, artísticocultural, científico-técnico y jurídico-político, en los que en uno o en todos pueden encuadrase a los miembros de los comités.

Perfil ideológico. Para identificar la orientación ideológica conservadora o progresista de los 23 miembros de los comités que antes o después de su participación en las exposiciones nacionales o universales han sido miembros del gobierno, hemos empleado de referencia la orientación política del presidente del gobierno, agregando en un bloque los gobiernos progresistas y de la unión liberal y en otros los gabinetes moderados y conservadores.

Tabla 1. Perfil de los miembros de los comités españoles en las exposiciones económicas en el reinado de Isabel II

\begin{tabular}{|c|c|c|}
\hline Participación & En una o & Expos. industriales de Madrid 1828, \\
& dos exposiciones & $1841,1845,1850$. \\
en & En tres & Expo. agrícola de 1857 \\
exposiciones & exposiciones & Expos. universales de Londres y París 1851, \\
& En más de & 1855,1862 y 1867. \\
\hline \multirow{2}{*}{ Perfil } & cuatro & Proyecto Expo. Hispanoamericana de Madrid 1859 \\
generacional & G. liberal & nacidos entre 1770 y 1789 \\
& progreso & nacidos entre 1790 y 1809 \\
& nacidos entre 1810 y 1829 \\
\hline
\end{tabular}

2 A la generación del progreso, los nacidos entre 1790 y 1809, utilizando periodos también de 20 años, se añaden los siguientes cortes generacionales: a) La generación Liberal, protagonista del Trienio y del Estatuto, que agrupa a los nacidos entre 1770 y 1789 , tendrán una posición decisiva en Cádiz, que comparten con la última generación ilustrada. b) La generación demócrata, que desempeñara una posición central en el sexenio democrático y en el diseño de la restauración, integra a los nacidos entre 1810-1829. 


\begin{tabular}{|c|c|c|}
\hline & $\begin{array}{c}\mathrm{G} . \\
\text { demócrata }\end{array}$ & \\
\hline \multirow{3}{*}{$\begin{array}{c}\text { Perfil } \\
\text { profesional }\end{array}$} & $\begin{array}{c}\text { Perfil } \\
\text { Artístico-Cultural }\end{array}$ & $\begin{array}{l}\text { Agencias públicas: Universidad. Institutos. Museo } \\
\text { del Prado, Museo Nacional de Pintura } \\
\text { Corporaciones y asociaciones: Academia Española, } \\
\text { de la Historia, de Bellas Artes Academia de la Buenas } \\
\text { Letras, de Arqueológica. Ateneo, Liceo Artístico. } \\
\text { Periódicos. }\end{array}$ \\
\hline & $\begin{array}{c}\text { Perfil } \\
\text { Científico-técnico }\end{array}$ & $\begin{array}{l}\text { Administración pública: Consejo de Agricultura y } \\
\text { Comercio, de Administración, de Instrucción Pública } \\
\text { Agencias públicas: Universidad, Escuelas } \\
\text { arquitectura, ingeniería, veterinaria. Museo de Ciencias } \\
\text { Naturales, Jardín botánico, Observatorio, Conservatorio } \\
\text { de Artes-Instituto Industrial, Comisión de Estadística, } \\
\text { Comisión de Pesas y Medidas, Comisión del Mapa de } \\
\text { España; del Mapa Geológico; del Mapa Forestal } \\
\text { Sociedades de cultura científica: Academia de } \\
\text { Ciencias, A. de Medicina, de Ciencias morales y Políticas } \\
\text { Sociedades Económicas de amigos del País. } \\
\text { Empresas y corporaciones privadas: Sociedad de } \\
\text { socorros mutuos, Cajas de ahorro, Banco de España, } \\
\text { Ferrocarril/alumbrado/seguros, Asociación empresarial, } \\
\text { Junta de comercio, Corporaciones profesionales }\end{array}$ \\
\hline & $\begin{array}{c}\text { Perfil } \\
\text { Jurídico-político }\end{array}$ & $\begin{array}{l}\text { Administración pública: Empleado Público, } \\
\text { Embajador. Gobernador. Director general. Subsecretario. } \\
\text { Consejo de Estado } \\
\text { Corporaciones y agencias: Universidad. Academia } \\
\text { de Jurisprudencia, A. de Ciencias Morales } \\
\text { Concejal/alcalde. } \\
\text { Juez. Fiscal. Tribunal Supremo (Consejo Real) } \\
\text { Diputado. Senador } \\
\text { Ministro. Presidente del Gobierno }\end{array}$ \\
\hline $\begin{array}{c}\text { Perfil } \\
\text { ideológico }\end{array}$ & $\begin{array}{l}\text { Progresista. } \\
\text { Moderado }\end{array}$ & $\begin{array}{l}\text { Orientación política del presidente del gobierno en } \\
\text { los gabinetes de los que forman parte los miembros de las } \\
\text { comisiones que han sido o serán ministros: Gobierno } \\
\text { Progresista y de la Unión liberal. Moderado y } \\
\text { Conservador }\end{array}$ \\
\hline
\end{tabular}

Fuente. Elaboración propia.

El término progreso se emplea de forma polisémica. Se refiere a la idea del progreso que se incorpora a la agenda pública frente al modelo de la experiencia, que prefería la imitación de los antiguos. Con el progreso, los modernos percibirán cada etapa como un avance para alcanzar la prosperidad y el bienestar (Gomá, 2003), un aspecto clave de la visión del mundo de los nacidos en torno a 1800, lo que nos permite denominarlos la generación del progreso. Además, nos referimos también al Partido Progresista, y a los periodos en los que gobierna.

Para estudiar la intensidad de la politica para la sociedad industrial a través del impulso de las exposiciones económicas se hace un balance de los documentos publicados en La Gaceta de Madrid y en los Boletines Oficiales de algunas provincias. 


\section{UNA POLÍTICA PARA LA SOCIEDAD INDUSTRIAL}

Entre 1833 y 1868 en España se adoptó una politica pública orientada a favorecer el desarrollo técnico-industrial. Una politica para la sociedad industrial en la que se puede identificar un extenso elenco de actores; Unos privados como las sociedades mineras, las empresas concesionarias de ferrocarriles, las industrias que participan en las exposiciones industriales; Otros actores igualmente privados, con funciones públicas como las sociedades de cultura científica, las corporaciones económicas, los partidos políticos o la prensa; Y además un amplio elenco de actores del ámbito público que van desde el Gobierno, a las Cortes, o al Ministerio de Fomento y de las agencias de innovación como la Comisión de Pesos y Medidas o el Conservatorio de Artes, transformado en Instituto Industrial, hasta las exposiciones económicas.

Los problemas que se incorporan en la agenda pública, las decisiones que se adoptan, como se ponen en marcha, y cuáles son los procesos de evaluación integran un conjunto de cuestiones, de distinta envergadura que constituyen un catálogo para la sociedad industrial, un temario para el progreso en el que la minería estaba llamada a ser una las principales fuentes de riqueza de España, y que se extiende a otras cuestiones como la diversidad de los sistemas tradicionales de pesos y medias, que es vista como una cuestión de indudable repercusión política, social y económica, o las características del despliegue de la red de ferrocarril, y su conexión con el sistema de comunicaciones, incluido el telégrafo cuya vinculación con el desarrollo económico y social, se ha puesto repetidamente de manifiesto. Aspectos todos ellos que se convertirán en una de las cuestiones más relevantes de la acción pública en el tercio central del XIX, junto a los problemas de formación de capital humano que se verán como un lastre para las posibilidades de la sociedad industrial. Así como otras cuestiones vinculadas con la politica urbanística, el abastecimiento de agua, o la cuestión de los bosques que completan una relación de problemas, de aspectos que no pretenden integrar una lista exhaustiva, sino que se presenta como demostrativa de la existencia una agenda pública, consciente y coherente, que configuró un proyecto para la sociedad industrial.

En todo caso, con independencia de las lineas maestras de la politica económica, como la desamortización o el debate librecambista, vinculadas al desarrollo del marcado nacional, para promover el fomento y mejora de la economía, se impulsó un programa deudor de la administración fernandina, orientado a la celebración de exposiciones primero nacionales y luego internacionales. Un foro industrial y agrario, para presentar y premiar los avances en la maquinaria y producción en textil, en la metalurgia, en la minería, en la química industrial, y en la agricultura y ganadería.

En el tercio central del XIX, entre 1833 y 1868, se constituyen y recuperan una pluralidad de organizaciones y corporaciones científicas-técnicas y económicas que, en el marco de la Constitución de 1837, contribuyen a configurar las características del Estado liberal y de la sociedad industrial.

Frente al absolutismo la institucionalización del progreso permite cumplir el programa liberal de ruptura con antiguo régimen. La idea del progreso ayuda a explicar la estructura, las pautas y el recorrido del Estado liberal y de la sociedad industrial cuya configuración con esta interpretación se presenta menos dependiente del liberalismo doctrinario o de la década prodigiosa del derecho 
administrativo. Las instituciones del progreso son un diseño de la política liberal que articula, intimamente conectadas, una política para la ciencia y una política para la sociedad industrial (Tabla 2).

En esta politica destacan las instituciones estatales con las que se impulsan nuevas organizaciones y estructuras públicas y privadas para desarrollar nuevas o renovadas políticas para la sociedad industrial. Entre ellas, quizá la más importante es la consolidación del Ministerio de Fomento y de los gobiernos provinciales, y junto a los nuevos actores de la administración liberal, las agencias públicas de innovación, sobre todo el renovado Instituto Industrial, heredero del Conservatorio de Artes, que tendrá "entre las actividades de mayor proyección las Exposiciones públicas de los productos de la industria española, todas realizadas en sus locales: las cinco primeras (1827, 1828, 1831, 1841 y 1845), en las instalaciones de la calle del Turco; la sexta en el ex convento de la Trinidad (1850), justo cuando se va a transformar en el recién creado Instituto Industrial” (Ramón Teijelo \& Silva Suárez, 2007, pág. 276)

Tabla 2. El progreso es un diseño de la politica (1833-1868).

\begin{tabular}{|l|l|}
\hline \multicolumn{1}{|c|}{ Una política para la ciencia. } & Una política para la sociedad industrial. \\
\hline \multicolumn{1}{|c|}{ El Ministerio de Fomento } & \multicolumn{1}{|c|}{ El Ministerio de Fomento } \\
La Universidad científica & \multicolumn{1}{c|}{ Agencias públicas de innovación: } \\
- Facultad completa de Filosofía. & -Comisión de Pesos y medidas \\
- Grado de Ciencias & -Instituto Industrial \\
- Secciones de Ciencias en la Facultad de & \multicolumn{1}{|c}{ Formación de capital humano: } \\
Filosofía & - Escuelas de Ingenieros \\
- Facultad de Ciencias. & - Formación técnica profesional \\
Las Academias de Ciencias. & \multicolumn{1}{c}{ Políticas sectoriales de innovación } \\
- Recuperación de la Academia de & técnica (entre otras): \\
Ciencias Naturales de Barcelona. & - Exposiciones económicas \\
- Academia de Ciencias Naturales de & - Ferrocarril. \\
Madrid. & - Minería. \\
- Academia de Ciencias Exactas, Físicas & - Montes. \\
y Naturales. & - Agua. \\
Agencias públicas de investigación & - Urbanismo. \\
- Comisión del Mapa Geológico. & - Telégrafo eléctrico. \\
- Junta de la Carta cartográfica. & Corporaciones económicas \\
- Comisión General de Estadística. & - Junta de Comercio de Barcelona \\
Sociedades de cultura científica & - Junta de Comercio de Las Palmas \\
- Recuperación de las Sociedades de & - Junta de Comercio de Valencia. \\
Amigos del País & - Instituto Industrial de Cataluña \\
- Recuperación del Ateneo de Madrid & - Instituto Agrícola Catalán de San \\
- Sociedad Literaria de Fomento y Recreo & Isidro \\
- de Las Palmas de Gran Canaria & \\
- Sociedad de Instrucción Pública & \\
\hline
\end{tabular}

Fuente. Elaboración propia. 


\subsection{La intensidad de la acción gubernamental.}

El alcance o la importancia de una política pública o al menos la expresión del esfuerzo gubernamental puede medirse por los recursos públicos puestos a su disposición, por el tipo o por los objetivos de las decisiones que se adopten o por la intensidad de su presencia en los medios de comunicación públicos o privados.

Figura 1. Intensidad de la acción gubernamental en el fomento de las exposiciones económicas

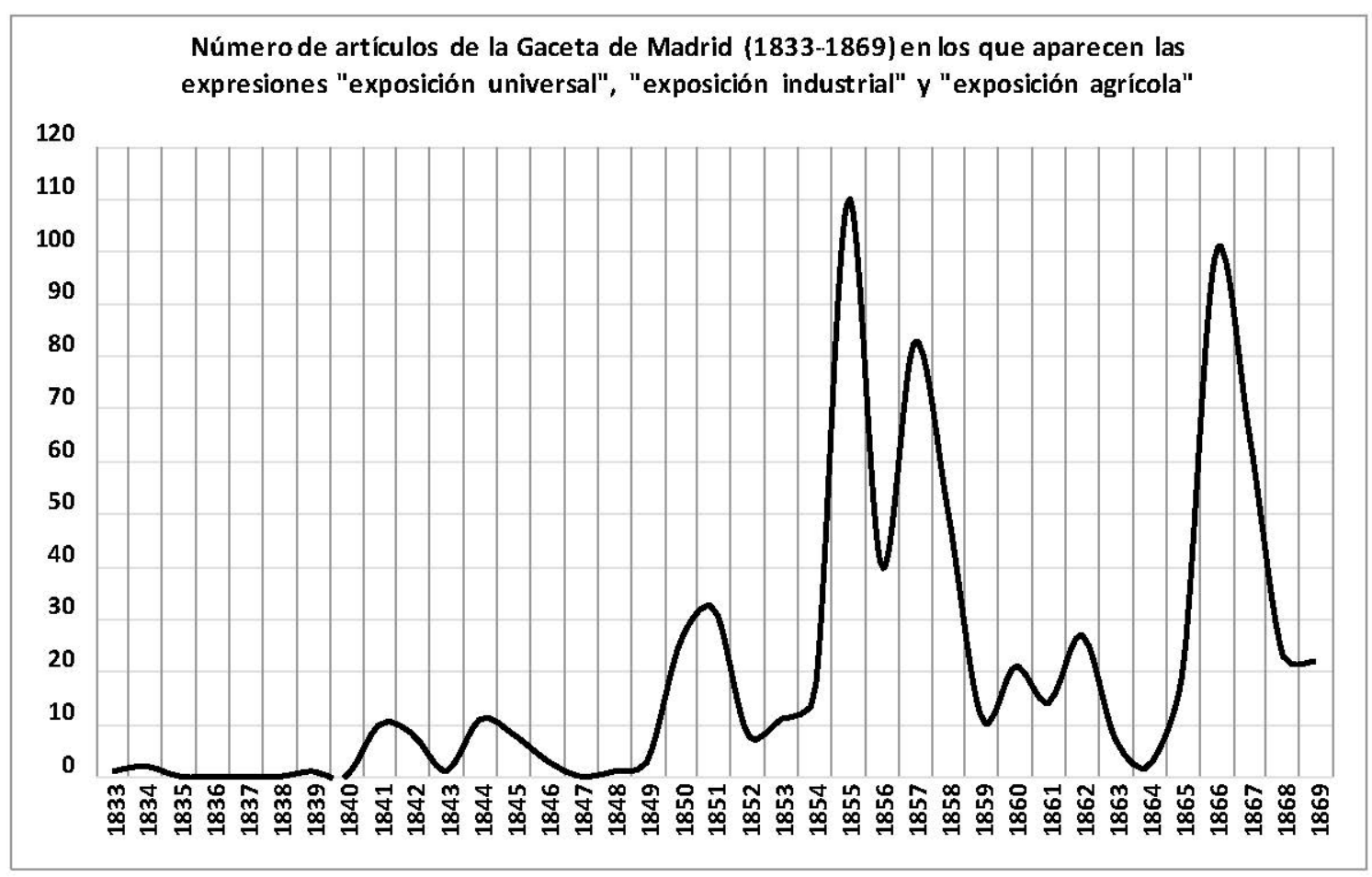

Fuente. Elaboración propia a partir de la colección de la Gaceta de Madrid (BOE)

Si se mide la intensidad de la acción de los poderes públicos por el volumen de su aparición en La Gaceta, la política para la sociedad industrial mediante el fomento de las exposiciones se incrementó sustancialmente a partir de 1850. La serie de los 736 artículos publicados en la Gaceta de Madrid $^{3}$ que recogen las

\footnotetext{
${ }^{3}$ Desde 1836 por la Real orden circular a todas las autoridades del reino, mandando que todos los Reales decretos, órdenes é instrucciones del Gobierno que se publiquen en la Gaceta bajo el artículo oficial, sean obligatorios desde el momento de su publicación para toda clase de personas (Gaceta de Madrid de 22 de septiembre de 1836) la Gaceta se convirtió en el principal instrumento de transparencia de las decisiones de los poderes públicos, pero hasta 1908, además de la sección oficial, mantuvo algún espacio de información no oficial semejante a los periódicos privados y que según las épocas incluía opinión, transcripción de los debates parlamentarios, noticias internacionales, nacionales, culturales, cientificas, reseñas de libros, información meteorológica, espectáculos, santoral, avisos, etc.. Y no será hasta 1909 con la Real orden aprobando la instrucción para el régimen y administración de la GACETA DE MADRID, y disponiendo rija, desde la fecha de su autorización (Gaceta de 13 de junio de 1909) cuando las secciones tendrán un carácter estrictamente oficial.
} 
expresiones ${ }^{4}$ exposición universal, industrial, y agrícola (Figura 1) tiene una gran variabilidad temporal, recoge sobre todo artículos vinculados a las exposiciones universales, que agrupan un 65\% del total de documentos de La Gaceta. Destacan tres momentos de máxima acumulación: 1855, 1857 y 1866 son los años que acumulan una mayor frecuencia de documentos, un volumen que se refiere a las dos exposiciones universales de Paris y a la Exposición agrícola nacional de 1857. Las dos exposiciones de Londres, 1851 y 1862, y sobre todo las exposiciones nacionales anteriores a 1850 tuvieron una plasmación en la Gaceta mucho más reducida.

\subsection{E1 Gobierno durante las exposiciones universales del reinado de Isabel II}

En el reinado de Isabel II, en las décadas centrales del XIX, en función de la orientación politica gubernamental se pueden distinguir tres etapas: En la década de las regencias (1833-1843), un periodo convulso marcado por la guerra civil, los gobiernos progresistas y moderados tienen una presencia relativamente equilibrada, mayor para los progresistas (63\%) y algo menor para los moderados (37\%); por el contrario, en la década moderada, los gobiernos de derechas (moderados y autoritarios) abarcan un $97 \%$. Y por último, desde la Vicalvarada, que en 1854 abrirá el bienio progresista, hasta la revolución de 1868, que dará fin al reinado de Isabel II, ambos polos ideológicos, volverán a tener una presencia gubernamental equilibrada. El centroizquierda, la suma de los progresistas y la Unión Liberal, gobernó durante el $40 \%$ y la derecha el $60 \%$.

Tabla 3. Los ministros durante las exposiciones universales en el reinado de Isabel II

\begin{tabular}{|c|c|c|}
\hline $\begin{array}{l}\text { EXPOSICIÓN } \\
\text { UNIVERSAL }\end{array}$ & MINISTRO DE FOMENTO & $\begin{array}{l}\text { PRESIDENTE DEL } \\
\text { GOBIERNO }\end{array}$ \\
\hline \multirow{4}{*}{$\begin{array}{l}\text { Londres } 1851 \\
1 \text { de mayo a } \\
15 \text { de octubre }\end{array}$} & $\begin{array}{l}\text { Manuel SEIJAS LOZANO (1) } \\
(20.10 .1849 \text { al } 29.11 .1850)\end{array}$ & \multirow{2}{*}{$\begin{array}{l}\text { Ramón } M^{a} \text { Narváez } \\
(20.10 .1849 \\
\text { al10.01.1851) }\end{array}$} \\
\hline & $\begin{array}{l}\text { Saturnino CALDERÓN COLLANTES } \\
\text { (1) }(29.11 .1850 \text { al } 14.01 .1851)\end{array}$ & \\
\hline & $\begin{array}{l}\text { Santiago FERNÁNDEZ NEGRETE (1) } \\
(14.01 .1851 \text { al 5.04.1851) }\end{array}$ & \multirow{2}{*}{$\begin{array}{l}\text { Juan Bravo Murillo } \\
(14.01 .1851 \text { al } \\
14.12 .1852)\end{array}$} \\
\hline & $\begin{array}{l}\text { Fermin ARTETA SESMA (2) } \\
(5.04 .1851 \text { al } 20.10 .1851)\end{array}$ & \\
\hline \multirow{2}{*}{$\begin{array}{l}\text { Paris } 1855 \\
15 \text { de mayo a } \\
15 \text { de } \\
\text { noviembre }\end{array}$} & $\begin{array}{l}\text { Agustín ESTEBAN COLLANTES } \\
(19.09 .1853 \text { al } 17.07 .1854)\end{array}$ & $\begin{array}{l}\text { Luis José Sartorius } \\
(19.09 .1853 \\
\text { al17.07.1854) }\end{array}$ \\
\hline & $\begin{array}{l}\text { Francisco de LUXÁN MIGUEL- } \\
\text { ROMERO } \\
(30.07 .1854 \text { al } 6.06 .1855)\end{array}$ & $\begin{array}{l}\text { Baldomero Espartero } \\
(19.07 .1854 \text { al } \\
14.07 .1856)\end{array}$ \\
\hline
\end{tabular}

${ }^{4}$ A diferencia de otras publicaciones periódicas en La Gaceta se emplea siempre exposición. 


\begin{tabular}{|c|c|c|}
\hline & $\begin{array}{l}\text { Manuel ALONSO MARTÍNEZ } \\
(6.06 .1855 \text { al } 15.01 .1856)\end{array}$ & \\
\hline \multirow{3}{*}{$\begin{array}{l}\text { Londres } 1862 \\
1 \text { de mayo a } 1 \\
\text { de noviembre }\end{array}$} & $\begin{array}{l}\text { Rafael de BUSTOS Y CASTILLA } \\
(30.06 .1858 \text { al } 21.11 .1861)\end{array}$ & \multirow{3}{*}{$\begin{array}{l}\text { Leopoldo O`Donnell } \\
(7.11 .1859 \mathrm{al} \\
2.03 .1863)\end{array}$} \\
\hline & $\begin{array}{l}\text { José POSADA HERRERA (interino) } \\
(21.11 .1861 \text { al } 18.12 .1861)\end{array}$ & \\
\hline & $\begin{array}{l}\text { Antonio de AGUILAR Y CORREA } \\
(18.12 .1861 \text { al } 17.01 .1863)\end{array}$ & \\
\hline \multirow[t]{2}{*}{$\begin{array}{l}\text { París } 1867 \\
1 \text { abril al } 31 \\
\text { de octubre }\end{array}$} & $\begin{array}{l}\text { Antonio AGUILAR Y CORREA } \\
(21.06 .1865 \text { al 10.07.1866) }\end{array}$ & $\begin{array}{l}\text { Leopoldo O־Donnell } \\
(21.06 .1865 \mathrm{al} \\
10.07 .1866)\end{array}$ \\
\hline & $\begin{array}{l}\text { Manuel de OROVIO ECHAGÜE } \\
(10.07 .1866 \text { al 23.04.1868) }\end{array}$ & $\begin{array}{l}\text { Ramón } M^{a} \text { Narváez } \\
(10.07 .1866 \text { al } \\
23.04 .1868)\end{array}$ \\
\hline \multicolumn{3}{|c|}{ (1) Ministro de Comercio, Instrucción y Obras Públicas } \\
\hline
\end{tabular}

Fuente. Elaboración propia. Las fechas de los ministerios provienen del Diccionario biográfico de los ministros españoles (Urquijo, J.R.;2004) En azul gobiernos de centroizquierda (Espartero y O`Donnell). En naranja los gobiernos de derechas (Narváez, Bravo Murillo y Sartorius)

En la Tabla 3 se presenta el color político del gobierno durante las exposiciones universales, junto a la continuidad de la participación española destaca la discontinuidad de la intensidad gubernamental. En las exposiciones universales es notable la diferencia de los distintos ministros.

En la primera exposición de Londres, los gobiernos presididos por Narváez o por Bravo Murillo incrementaron el esfuerzo gubernamental. Durante la exposición el ministro de Fomento, Fermin Arteta $^{5}$, era un politico conservador, tecnócrata avant la lettre (Trena, 1971)

En la de París de 1855, en el gobierno del bienio, presidido por Espartero, el ministro de Fomento, Francisco de Luxán ${ }^{6}$, un científico y político progresista (Luxán Meléndez J. , 2016), que consolidó el trabajo previo, y su mandato, en 1855, fue el de mayor intensidad de la acción gubernamental. La Gaceta publicó 110 documentos vinculados con exposiciones económicas, de ellos

5 Fermín de Arteta y Sesma (1796-1880). Ingeniero Militar. Profesor de geometría descriptiva y dibujo militar de la academia de ingenieros de Guadalajara en 1836 y 1837. Diputado del partido Moderado en 1837, 1839, 1844 y 1846. Senador vitalicio en 1849. Jefe Politico de Navarra y Madrid. Gobernador civil de Barcelona en $1850 . \quad$ En 1851 ministro con Bravo Murillo de Gobernación y luego de Comercio, Instrucción y Obras Públicas. (Urquijo Goitia M. 2010 y 2013).

6 Francisco de Luxán Miguel-Romero (1799-1867). Mariscal de Campo, artillero, vicepresidente de la Real Academia de Ciencias, dirigente del Partido progresista, diputado, senador, ministro de Fomento, consejero de Estado y miembro del Consejo de Administración del Banco de España. 
108 con la exposición universal de París. En un contexto de profunda renovación ministerial destaca la continuidad de los responsables del fomento de la industria a través de las exposiciones. El ministro de Fomento confirmó a todos $^{7}$ los miembros del Comité español encargado de la participación en la exposición e igualmente revalidó al director general, José Caveda, competente en el área de agricultura, industria y comercio.

En la de Londres de 1862, la de menor intensidad de la proyección en la Gaceta, durante el gobierno largo de O`Donnell, ocupa la cartera de fomento Antonio de Aguilar ${ }^{8}$ que luego será presidente del Consejo de Ministros. Y finalmente durante la exposición de Paris de 1867, en el último gobierno de Narváez que recuperó el esfuerzo de comunicación a través de la Gaceta, fue ministro de Fomento Manuel de Orovio9.

\subsection{El papel de los gobiernos provinciales}

Junto a la consolidación del ámbito del Ministerio de Fomento ${ }^{10}$ en el ámbito de la política para la sociedad industrial es igualmente relevante la definitiva implantación de la división provincial (Burgeño, 1996, págs. 158-167) y la articulación de la administración periférica, de los gobiernos provinciales, primero subdelegados de fomento, luego jefes políticos y más adelante gobernadores civiles, a los que Javier de Burgos reservó por un relevante papel de agentes de la prosperidad, de impulso de las sociedades de cultura científica, entre ellas, las sociedades de amigos del país o las corporaciones como las Juntas de Comercio, responsables de gran parte de las exposiciones económicas de ámbito local. Además, desde 1834, los gobiernos provinciales editaran un Boletin Oficial ${ }^{11}$ que junto a la Gaceta de Madrid conformaran una

7 Sólo se produjo un cambio inevitable. El presidente del Comité, Fernando Muñoz Duque de Riánsares-, segundo marido de la reina Cristina, expulsada de España en 1854, y que fue sustituido por Vicente Sancho y Cobertores (1784-1860) un destacado dirigente progresista que habia sido presidente del gobierno en septiembre de 1840 .

${ }^{8}$ Antonio de Aguilar y Correa (1824-1908), marqués de la Vega de Armijo, jurista, político liberal, diputado, ministro de Gobernación, de Fomento, de Estado. Presidente del Consejo de Ministros entre 1906 y 1907. De la Real Academia de la Historia y de la de Ciencias Morales y Politicas. (Cuenca Toribio, Antonio Aguilar Ochoa y Correa, 2020).

9 Manuel de Orovio Echagüe (1817-1883). Jurista. Político conservador, diputado, ministro de Hacienda y Fomento. Responsable de la expulsión de la universidad de Castelar, de Salmerón y luego de Giner de los Ríos. (Cuenca Toribio, Manuel Orovio y Echagüe, s.f.)

10 Todavía en la administración Fernandina el Ministerio de Fomento se crea en 1832 con la denominación Secretaría de Despacho de Fomento General del Reino que se convertiría en 1833 en el Ministerio de Fomento General del Reino, luego en 1834 Ministerio de Interior, de Gobernación en 1835, y desgajado de interior en 1847 como Ministerio de Comercio, Instrucción y Obras Públicas (Pérez Juan, 2008) que se denominará en 1851 Ministerio de Fomento. Para una visión de conjunto de la evolución de los órganos centrales la administración española en el reinado de Isabel II ver la síntesis de Baena sobre el Origen y Consolidación de la Administración Liberal Española (Baena del Alcázar, 2012, págs. 109$117)$.

11 En el prospecto del Boletín Oficial de Canarias (1 de junio de 1834) se anuncian cuáles serán sus contenidos: Primero. Artículo de oficio; bajo este epígrafe se publicarán las órdenes y circulares del gobierno, con las prevenciones particulares que las Autoridades delegadas en esta Provincia crean deber hacer para facilitar su cumplimiento; órdenes circulares que 
red de medios de comunicación públicos, que junto a la difusión de las disposiciones e instrucciones oficiales estatales o provinciales publicará artículos sobre agricultura, artes o comercio, y otras informaciones.

Figura 2. Intensidad de la acción de los gobiernos provincials

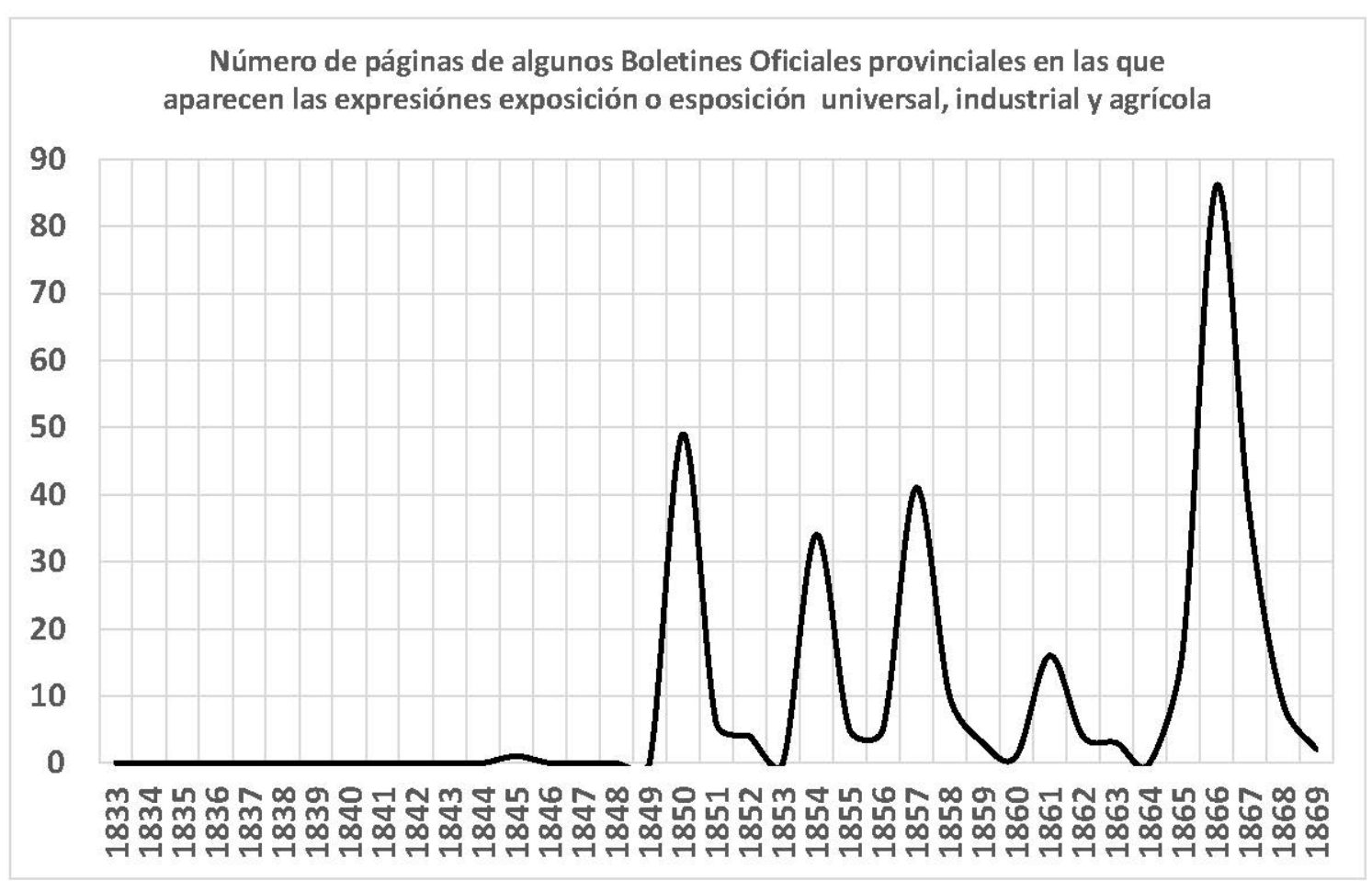

Fuente. Elaboración propia a partir de la Biblioteca virtual de prensa histórica del Ministerio de Cultura (MCU) y del Archivo de prensa digital de Canarias en la Universidad de las Palmas de Gran Canaria (JABLE): Boletín oficial de la provincia de Badajoz, Barcelona, Canarias, Murcia, Orense, Oviedo, Palencia, Santander, Soria, y Zamora

Al igual que con el gobierno central si se mide la intensidad de la acción de los poderes provinciales por el volumen de su aparición en Boletines Oficiales, la politica para la sociedad industrial mediante el fomento de las exposiciones se incrementó sustancialmente a partir de 1850. La serie de los 332 artículos publicados en Boletines que hemos podido procesar que recogen las expresiones exposición o exposición universal, industrial, y agrícola (Figura 2) tiene una gran variabilidad temporal, recoge sobre todo artículos vinculados a las exposiciones universales.

estas Autoridades expidan en todos los ramos de la Administración, y los anuncios que pertenezcan al Real servicio como ventas, arriendos, subastas etc. Segundo, Los artículos para que quedare lugar, relativos a la agricultura, artes o comercio, y que sean de un interés más inmediato a estas Islas, y los que en todas materias y con sujeción a lo dispuesto en la ley de libertad de imprenta, se dirijan al redactor, parara inserción en el Boletín. Tercero, Últimamente se colocarán todos los avisos de mayor interés a el comercio y agricultura como salidas da correos, buques a la carga, ventas, llegadas de buques y el cargamento etc. 
Destacan seis momentos de máxima acumulación: 1850, 1854, 1857, 1861 y 1866 son los años que acumulan una mayor frecuencia de documentos, un volumen que se refiere a las exposiciones universales, a la Exposición agrícola nacional de 1857, y a la exposición nacional de 1850 tan conectada con la de universal de Londres de 1851.

\section{LAS EXPOSICIONES DE FOMENTO DE LA SOCIEDAD INDUSTRIAL}

La relevancia de las exposiciones de fomento de la sociedad industrial abarca un periodo más amplio que el reinado de Isabel II. "Desde los años centrales del siglo XIX y hasta el comienzo de la Primera guerra Mundial las exposiciones (universales, nacionales o regionales), las exhibiciones y las ferias industriales fueron los grandes vehículos de comunicación a gran escala de los progresos de las técnicas y del desarrollo de las industrias nacionales" (Esteban Piñero, 2019, pág. 71).

\subsection{Tipologia: Estado y Sociedad Civil}

Al presentar las exposiciones económicas del periodo isabelino, en las décadas centrales del XIX, es habitual subrayar una dicotomía global-local que por su fuerza y novedad distingue todas las demás de las exposiciones universales de Londres ${ }^{12}$ en 1851 y 1862 y las de Paris ${ }^{13}$ en 1855 y 1867. E igualmente se distingue entre exposiciones generales y especializadas. Este doble binomio se puede matizar si añadimos un segundo elemento institucional que destaque las diferencias entre las exposiciones de iniciativa estatal, y las de iniciativa civil (tabla 4).

El interés por la idea de globalización para sintetizar el carácter de las exposiciones universales lo encontramos de forma muy temprana. Por ejemplo, el ministro Luxán sobre la Exposición Universal de Londres de 1851, resalta los valores de las políticas del Estado Liberal, y el alcance del cambio técnico en la configuración de la sociedad industrial. Una reflexión que adelantó en 1837 al señalar que los ciudadanos los son ya del globo ${ }^{14}$.

12 Entre las memorias sobre las exposiciones de Londres se pueden destacar la de Luxán (Luxán Miguel-Romero, 1863) y sobre el ferrocarril la de Montesino. (Montesino, 1863).

13 Lasheras en su tesis doctoral describe detalladamente las condiciones y características de la participación española y las instrucciones de La Comisión Central, encargada de organizar la concurrencia española a la exposición de 1855 (Lasheras Peña, 2009).

$14 \mathrm{El}$ carácter que distingue al siglo en que vivimos es la economía, velocidad y facilidad de comunicaciones... vivimos más en menos tiempo; de especies parasitas a un determinado país hemos pasado a las transmigradoras; de ciudadanos de una villa a serlo del globo...y todo demuestra la tendencia marcada a gastar las diferencias que distinguen las naciones, hermanarlas y reunir los diferentes grupos de nuestra especie separaos en vano por naturaleza (Luxán Miguel- Romero, 1837, págs. 4-5) En 1837 la expresión de que los ciudadanos ya son del globo no es nueva, por ejemplo en 1811 Flórez Estrada ya la usaba en su Examen imparcial de las disensiones de la América con España, de los medios de su reconciliación y de la prosperidad de todas las naciones (Florez Estrada, 1811). 
Ocurrió entonces que la sociedad actual habia pasado en un corto periodo de años, y casi insensiblemente, de un estado más o menos parecido al de la antigua civilización en que las transacciones sociales eran cortas y a largas fechas, los medios de locomoción y de comunicaciones lentos y aun peligrosos, las fuerzas vivas de que podia disponer el hombre, la gravedad, la fuerza animal, el movimiento de los fluidos del agua o del gaseoso de la atmósfera, a otro marcadisimo en el progreso de la humanidad y derivado del conocimiento del vapor como agente de fuerza $y$ de sus aplicaciones. En una palabra, del torno, de la palanca, del plano inclinado, de la caida de agua y de la vela del buque, el hombre como por encanto se halló con la máquina de vapor, con los rails y la locomotora que presentó á su actividad el genio de Watt y de Stephenson $y$ fue tal $y$ tan marcado el efecto producido en el ánimo de todos, que en 1855 la Francia reprodujo igual manifestación, y hoy en 1862 la Inglaterra de nuevo ha llamado á la Exposición que actualmente ha tenido lugar (Luxán Miguel-Romero,1863)

Pero además de las exposiciones universales, en España el reinado de Isabel II "se celebraron muchas otras ${ }^{15}$ nacionales, regionales y locales, organizadas por iniciativas institucionales de carácter muy diverso, y que tuvieron también un papel muy destacado en la difusión de innovaciones" (Capel Sáez, 2007, pág.152). Igualmente, en otros países se celebraron muchas otras de carácter nacional o local y al menos 24 internacionales ${ }^{16}$ que no contaron con una presencia española muy importante. Enn la Exposição Internacional do Porto de 1865 hubo 24 expositores españoles de un total de 3.139 (Wikipedia); Sin embargo la repercusión en la prensa española es bastante importante en la Hemeroteca Nacional (BNE) se recogen 275 páginas publicadas en 1865 con información sobre la exposición, por ejemplo "En la esposicion de Oporto están llamando la atención las manufacturas de las fábricas de Cataluña y algunas obras de talabartería y

15 Entre 1827 y 1936 se celebraron unas 170 exposiciones económicas (Capel Sáez, 2007, pág. 186).

16 París (Francia) - Exposición Industrial Francesa (1844); Birmingham (Inglaterra) Exposición de la Sociedad Británica (1849); Birmingham (Inglaterra) - Primera Exposición de Manufactureros Británicos (1849); Cork (Irlanda) - Irish Industrial Exhibition (1852); Nueva York (Estados Unidos). Exhibition of the Industry of All Nations (1853); Dublin (Irlanda) Great Industrial Exhibition (1853); Múnich (Alemania) - Allgemeine deutsche IndustrieAusstellung (1854); Melbourne (Australia) - Melbourne Exhibition (1854) (en conjunción con la Exposition Universelle (1855); Dublín (Irlanda) - Dublin International Exhibition (1855); Manchester (Inglaterra) - Art Treasures Exhibition (1857); Besançon (Francia) Exposition universelle (1860); Melbourne (Australia) - Victorian Exhibition (1861); Hamburgo (Alemania) - Exhibición Agrícola Internacional (1862); Ámsterdam (Países Bajos) Exposición Industrial Holandesa (1864); Filadelfia (Estados Unidos) - Great Central Fair for the US Sanitary Commission (1865); Oporto (Portugal) - Exposição Internacional (1865); Dublin (Irlanda) - International Exhibition of Arts and Manufactures (1865);Dunedin (Nueva Zelanda) - New Zealand Exhibition (1865); Melbourne (Australia) - Intercolonial Exhibition of Australasia (1866). Lista de exposiciones internacionales que han dado lugar a la construcción de edificios permanentes notables (Wikipedia) Sobre el de Nueva York en 1853 puede verse la Tesis doctoral de Gabriel Pardo (Pardo Redondo, 2017). 
ebanistería de las provincias de Galicia, do las cuales hubieran ido más trabajos a Oporto si hubiese habido más actividad en su envió." (El Lloyd español 3/10/1865). Y en la lista de expositores de la Exposition Universelle de Metz de 1861 yo no he visto ningún expositor español (L'Exposition universelle de Metz journal de l'agriculture, du commerce, de l'industrie et des beauxarts, varias fechas, marzo-septiembre de 1861).

En el año central del siglo la Exposición Industrial de Madrid tendrá un nuevo objetivo, no sólo perseguirá dar a conocer nuestros progresos en las manufacturas y las artes industriales, y constituirse como la ocasión de alentarlas con una rivalidad legitima y los aplausos del público, sino que se integrara en un marco industrial internacional, y continuara la exposición de la orden de $1850^{17}$ todavia una circunstancia, producida hoy por el espiritu del siglo, viene a darla, mayor precio, haciéndola más que otras veces útil y necesaria. Tal es el concurso industrial de todas las naciones preparado en Londres para el año 1851.

Junto a las universales son también de iniciativa estatal las exposiciones que el Conservatorio de Artes, luego Instituto Industrial, impulso en Madrid en $1841^{18}, 1845^{19}$ y 1850 , continuadoras de las exposiciones fernandinas de 1827 , 1828 y 1831, destacan la Exposición de Productos Agrícolas de la Península, Islas Adyacentes y posesiones ultramarinas celebrada en Madrid en 1857, o el proyecto frustrado de Exposición Iberoamérica (Gaceta de Madrid, 22-2-1859). Francisco de Luxán, vicepresidente de la Junta, en el acto de entrega de los premios de exposición de 1841, subraya "el porvenir a que está llamada esta nación magnánima al ver la variedad de productos industriales, su perfección y el arranque, la inquietud saludable, y el amor al trabajo, desarrollado en nuestro país, y como el genio del saber y del progreso social estimula y fomenta todos los elementos que constituyen hoy la riqueza y el valer del mundo civilizado". Adelantos, esperanza que vincula al final de la guerra civil, a la estrella feliz del vencedor de Luchana, del pacificador de Vergara, para concluir afirmando que "Europa y el mundo todo, verá que si la mano victoriosa de V. A. supo poner término á los males y las desgracias de la guerra, si supo darnos la paz que gozamos y afianzar nuestras libertades, obtenida esta paz ha sabido también

17 Real Orden del ministro Seijas de 29 de abril de 1850 dictando varias disposiciones relativas a la próxima exposición de la industria española que debe abrirse en Madrid el 1 de noviembre de 1850 (Boletín Oficial del Ministerio de Comercio, Instrucción y Obras públicas. N. ${ }^{\circ}$ 124. Año III de mayo de 1850).

18 La exposición se convocó el 16 de julio, para que abriera al público entre el 19 de noviembre y el 20 de diciembre de 1841, un periodo que resultó envuelto por en su inicio por la sublevación absolutista del 7 de octubre de 1841, y por el estado de sitio de Barcelona y al concluir por la fragmentación parlamentaria de los progresistas. La Junta señala las dificultades del contexto político, pero resalta el número y la calidad de los productos que acudieron a la exposición (Junta de calificación de la exposición, 1842).

${ }^{19}$ En un contexto de exclusión política de los progresistas, en 1845 el Conservatorio de Artes organizo la Exposición de 1845. En la exposición de 1845 los moderados incorporaron un mayor equilibrio generacional. Cambio generacional acompañado de un cambio en el origen profesional de los miembros del jurado, con una significativa reducción de los que tienen un perfil científico o técnico que le acompaña un incremento de la presencia de pesos pesados de la politica moderada. En 1845, con Javier de Burgos ocho serán o han sido ministros. 
animarlas artes, proteger la industria y abrir las fuentes del comercio, y levantar por fin la nación española al grado de esplendor y de grandeza á que le llaman sus destinos en el venturoso reinado de nuestra reina doña Isabel II" (Luxán Miguel-Romero, 1842)

La Exposición Agrícola de Madrid de 1857, en la estela del Palacio de Cristal de Londres de 1851, contó con un pabellón construido ex profeso en la montaña del Príncipe Pío, una línea que luego seguirá la de Barcelona de 1860. En la Exposición de 1857 se otorgaron tres medallas de oro con inscripción honorífica, a Francisco de Luxán, como ministro de fomento en 1856, a Claudio Moyano, como ministro de fomento en 1851, y a Pedro colon, como presidente del jurado de 1857.

En paralelo se celebraron un conjunto de exposiciones de iniciativa de la sociedad civil, de ámbito local o regional y de carácter general, o especializado en el ámbito industrial, o agrícola y ganadero organizadas con el impulso de las sociedades de cultura cientifica, como en Las Palmas ${ }^{20}$ o en Valencia por La Sociedad Literaria de Fomento y Recreo y las Sociedades de Amigos del País; o corporaciones como en Barcelona, la Junta de Comercio, el Instituto Industrial de Cataluña o el Instituto Agrícola Catalán de San Isidro.

Entre las de Barcelona la de la Casa de Lonja de 1844 (Junta de Comercio de Barcelona, 1844) o en la explanada de la ciudadela, en el llamado campo de marte, en octubre de 1860, la Exposición de Industria, Artes y Oficios (Orellana, 1860). En 1862, la de Las Palmas, a iniciativa de Manuel Ponce de León ${ }^{21}$, y con el liderazgo de La Sociedad Literaria, se celebró en las casas consistoriales de Las Palmas $^{22}$. En la de Valencia de 1867, la Exposición Regional de Agricultura, Industria y Montes, iniciativa de la Sociedad Valenciana de Amigos de País, el convento desamortizado de San Juan de Ribera, participaron las provincias de Alicante, Castellón, Valencia, Murcia y Albacete (Sánchez Romero , 2009, pág. 273 y siguientes).

Un buen ejemplo de colaboración público-privada, de interacción del Estado y la Sociedad Civil en la política para la sociedad industrial, fue la exposición de Agricultura, Industria y Artes de Las Palmas de 1862 para la que se constituyó una junta directiva en la que están presentes la sociedad civil y las instituciones públicas locales y estatales. La Junta de Las Palmas presidida por el Gobernador de la Provincia y en su defecto por e1Subgobernador del

\footnotetext{
${ }^{20}$ Las exposiciones de Artes e Industria de Las Palmas de 1849,1853 y 1856 tuvieron además de las bellas artes un componente artesanal. "La convocatoria de mayor transcendencia de toda la centuria fue la denominada Exposición Provincial de Agricultura, Industria y Artes de 1862" (Hernández Socorro, 2009, pág. 55).

${ }^{21}$ Manuel Ponce de León y Falcón (1812-1880), pintor, arquitecto y urbanista, no es exagerado identificar a Las Palmas del Ochocientos con la figura de Manuel Ponce de León y Falcón. Sin lugar a duda, estamos ante el artista más significativo de Gran Canaria de la era isabelina, sexenio democrático y de parte del período restauracionista, debiendo asignársele, por otra parte, un lugar destacado en el más amplio marco de la Historia del Arte de Canarias. (Hernández Socorro, Manuel Ponce de León y Falcón. Pintor Gran Canario, 1996, pág. 18).
}

22 En la exposición de Las Palmas de 1862 tuvo especial relevancia las labores del tabaco (Luxán Meléndez S. , 2006, págs. 161-162). 
Distrito, está formada por nueve miembros de La Sociedad Literaria de Fomento y Recreo; uno de la Diputación Provincial; dos de la Junta de Agricultura e Industria de la Provincia; dos del Ayuntamiento de Santa Cruz de Tenerife y del de las Palmas; dos de la Sociedad de Amigos del País de Las Palmas; uno de la Sociedad del Liceo y otro de la de la Unión de las Palmas (Junta directiva de la exposición de 1862, 1864, pág. 9) .

Tabla 4. Exposiciones económicas en el reinado de Isabel II

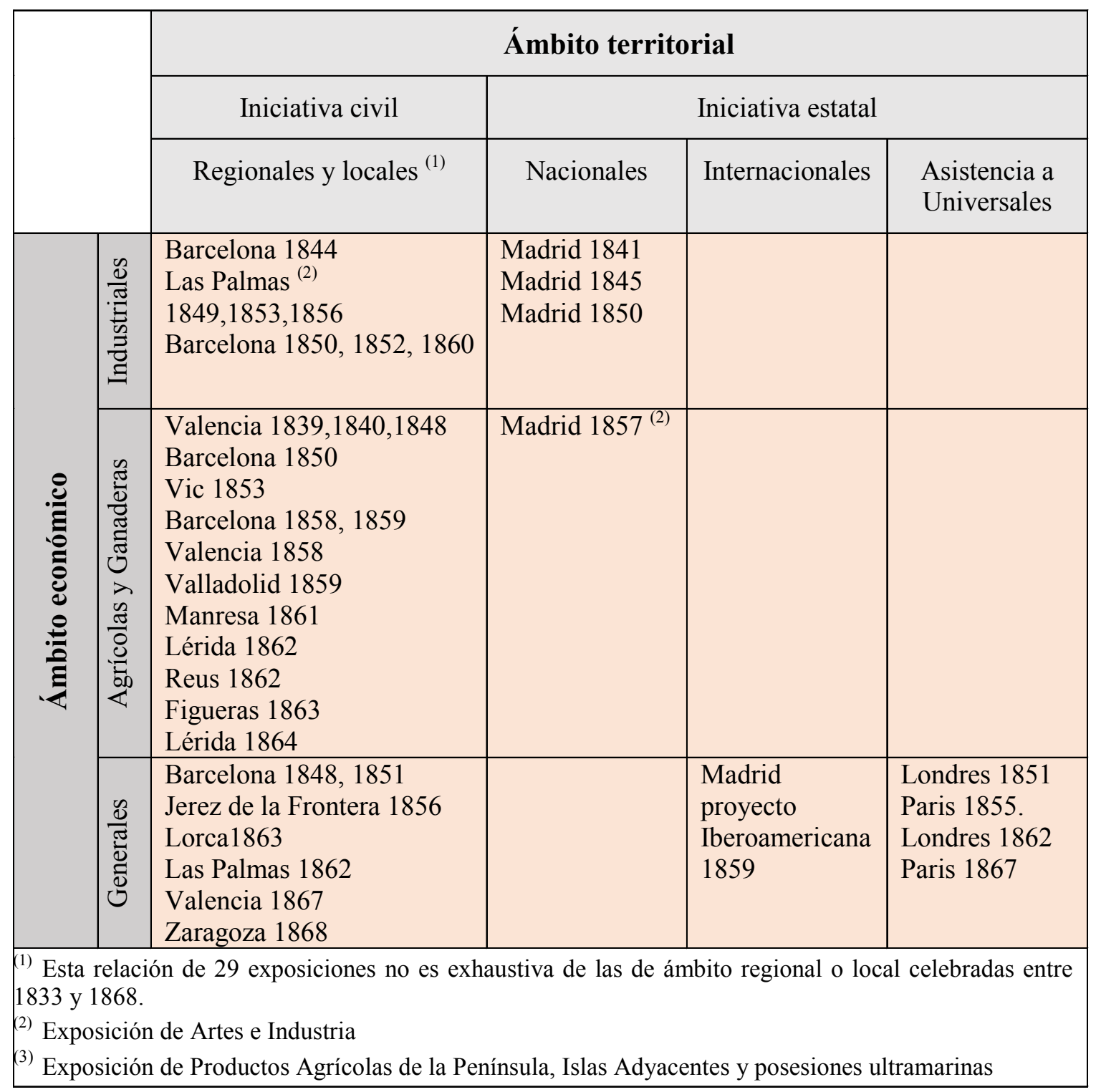

Fuente. Elaboración propia a partir del Archivo de prensa digital de Canarias JABLE, de Horacio Capel. Las exposiciones nacionales y locales en la España del siglo XIX (Capel Sáez, 2007) y María de los Reyes Hernández Socorro. Manuel Ponce de León (Hernández Socorro, Manuel Ponce de León y Falcón. Pintor Gran Canario,1996, págs. 69-79)

La exposición nacional de 1850 y la universal de 1851, más allá de que la de Madrid se configure como preparatoria de la de Londres, son una buena muestra del carácter continuo de ambos tipos de exposiciones. En ambas es decisiva la iniciativa estatal, y las dos cuentan con una comisión especializada, 
una comisión regia o una junta nombrada entre destacadas personalidades, a la que se asigna la administración del evento. Se trata de un modelo de administración participada que no se sustenta en una organización profesional estable, lo que no impide como en el caso español que esté intimamente conectada con el Instituto Industrial, una agencia pública de innovación, entre otras funciones, encargada del fomento de la industria.

Un modelo de gobernanza multinivel, y multisectorial que se extiende desde lo local hasta lo global, desde la generalidad a la especialización, en el que interactúan iniciativas estatales y de la sociedad civil, en un espacio de colaboración público privado, en el que con la designación personalidades científico-técnicas, del mundo de la cultura o de la política o con representantes de diversas instituciones civiles o públicas, se constituye para cada exposición comités, comisiones o juntas y jurados a los que se le atribuye el impulso del evento, y cuya gestión pude tener también una naturaleza público-privada. Un modelo institucional que se apoya en una red de comunicaciones en la que el ferrocarril, el telégrafo, y los periódicos son un nuevo y destacado exponente de la sociedad industrial.

Un artículo de fondo sobre la Exposición de París de 1867, publicado en $E l$ Isleño, un diario mallorquín, de carácter progresista, dirigido por José Gelabert Llabrés (1798-1866), destaca las implicaciones y a su juicio las contradicciones de la colaboración público-privado:

La comisión constituida para realizar en todos sus puntos el pensamiento de la Exposición universal representa la vez al Estado y a una sociedad particular. Considera al concurso internacional como un negocio y como una obra politica. Este carácter híbrido imprime al conjunto de las medidas adoptadas cierto matiz. de mercantilismo incompatible con el carácter oficial de la empresa y con su fin verdadero. Lo que distingue los negocios del Estado de los particulares, es que concebidos aquellos bajo un punto de vista de utilidad moral material, esencialmente colectiva, comprometen en cierto modo al pais $y$ exigen la ayuda del Tesoro público. ¿La Exposición pertenece a la primera o a la segunda de esas dos categorias? ¿Es de utilidad general o constituye una tentativa independiente? No puede haber duda: por su carácter de concurso internacional; por su fin, que es el progreso de todos los ramos de la producción; por sus medios, que en su mayor parte proceden directa indirectamente del impuesto, la Exposición universal, es una empresa nacional, una obra de hospitalidad, un medio de educación universal, un estimulante favorable al desarrollo intelectual moral. Bajo este concepto la Exposición universal debería ser absolutamente gratuita y accesible a todos; ninguna restricción debería imponerse a la publicidad de las obras expuestas, al estudio completo de los procedimientos, métodos, instrumentos, maquinas útiles, productos de artes y oficios, cuya exhibición es considerada justamente como la apología del género humano. Reducir a cuestión de ganancia un concurso al cual han sido invitados todos los artistas $e$ industriales del mundo; permitir que degenere en explotación mercantil semejante obra, es un verdadero error. El Isleño (6 de abril de 1867) 


\subsection{Los miembros de las comisiones españolas para las exposiciones nacionales y universales}

A partir de 1833, el cambio político, implicará nuevas pautas en el ámbito científico y técnico que suponen también la incorporación de la generación del progreso, un cambio que abre paso a la presencia relevante de dirigentes en la política que cuentan con un nuevo perfil científico-técnico y de dirigentes en las instituciones científico-técnicas con un perfil político.

Se ha señalado que "las nuevas élites promotoras de las Exposiciones Universales intercambiaban sus cargos en parlamentos, redacciones periodísticas, asociaciones culturales y benéficas, etc., constituyendo, en definitiva, un auténtico entramado de poder" (Viera, 2020, pág. 33). En el caso español durante el reinado de Isabel II los miembros de los jurados y de los comités españoles mayoritariamente forman parte de la generación del progreso, nacieron alrededor del ochocientos, tienen un perfil profesional científico-técnico, un fuerte componente jurídico-políticos, y una posición gubernamental muy destacada, ideológicamente entre los que han sido o serán ministros hay un equilibrio entre moderados y progresistas. El grupo que participa en la mayoría de las exposiciones es reducido; de un total de 164 biografias que hemos revisado, solo 21 de ellos, un 13\%, participaron en tres o más exposiciones y la mayor parte, un $66 \%$, sólo en una.

Para describir el perfil generacional de los miembros de los comités y jurados españoles los hemos agrupado en tres cohortes de edad, que hemos denominado generación liberal (nacidos entre 1770 y 1789), generación del progreso (nacidos entre 1790 y 1809) y generación demócrata (nacidos entre 1810 y 1829). Como era de esperar en cada exposición el peso de las generaciones (Figura 3) varía considerablemente y con el paso del tiempo los más jóvenes adquieren mayor protagonismo.

La generación dominante, la que aporta mayor número de miembros, de media un 57\%, es la generación del progreso, protagonista de la consolidación del Estado liberal y del proyecto de la sociedad industrial Un grupo que alcanza y desarrolla su madurez politica, social, económica e intelectual durante el reinado de Isabel II. Los hombres del progreso, nacidos alrededor del ochocientos, son un $72,7 \%$ en la exposición de 1841, y aunque progresivamente se verá reducida su presencia, todavia en la exposición de 1862, casi 20 años después, en la segunda universal de Londres son un $50 \%$, y solamente en 1867, la última del reinado de Isabel II, la segunda de París, su aporte se verá reducido a un 35\%. La generación del progreso es protagonista de una etapa que en el ámbito político se ha calificado de pos revolucionaria, un periodo en el que los progresistas conviven con la moderación del proyecto conservador y se enfrentan con su radicalización reaccionaria; una etapa que en la ciencia española se identifica por su carácter intermedio entre el colapso y la generación de sabios; que en la literatura o en las bellas artes se reconoce por el romanticismo; y que en el ámbito técnico estará marcada por el vapor, el carbón y el hierro, que conforman una etapa paleotécnica; un periodo que se encuadra en la revolución industrial y en la segunda globalización, una etapa en la que las exposiciones económicas sin perder un ámbito nacional se ampliaron para convertirse en universales.

La transformación de las reglas institucionales de la política estará acompañada de un importante cambio generacional, en el que los nuevos 
dirigentes sustituyen en muy poco tiempo a las elites de la generación precedente, que habian sido protagonistas del programa de la revolución liberal y que fue expulsada de las instituciones por el regreso del absolutismo y por la represión de la década ominosa. Los más mayores, los integrantes de la generación liberal, protagonista del Trienio y del Estatuto, nacidos sobre 1780, tuvieron una posición decisiva en Cádiz, compartida con la última generación ilustrada, de media un 10\%. En las exposiciones económicas, entre 1841 y 1850, este grupo mantuvo una participación muy relevante, en torno al 20\%, y su peso caerá de golpe en 1851, hasta no contar en 1862 y 1867 con ninguna representación.

La tercera generación en presencia, la generación en ascenso, los más jóvenes, en promedio un 33\% del total de miembros, pertenece a la generación demócrata, los nacidos sobre 1820, un grupo que desempeñará una posición central en el sexenio democrático y en el diseño de la restauración. Este grupo en 1841 todavía era minoritario, sólo un $6,1 \%$, y paulatinamente su peso será cada vez mayor, en la primera de Londres, la de 1851, representan un 29,6\%, y en la segunda de París, en 1867, cuando alcanzan la madurez, agrupan un $65 \%$.

Figura 3. Porcentaje por edades de los miembros de las comisiones españolas en las exposiciones nacionales y universales

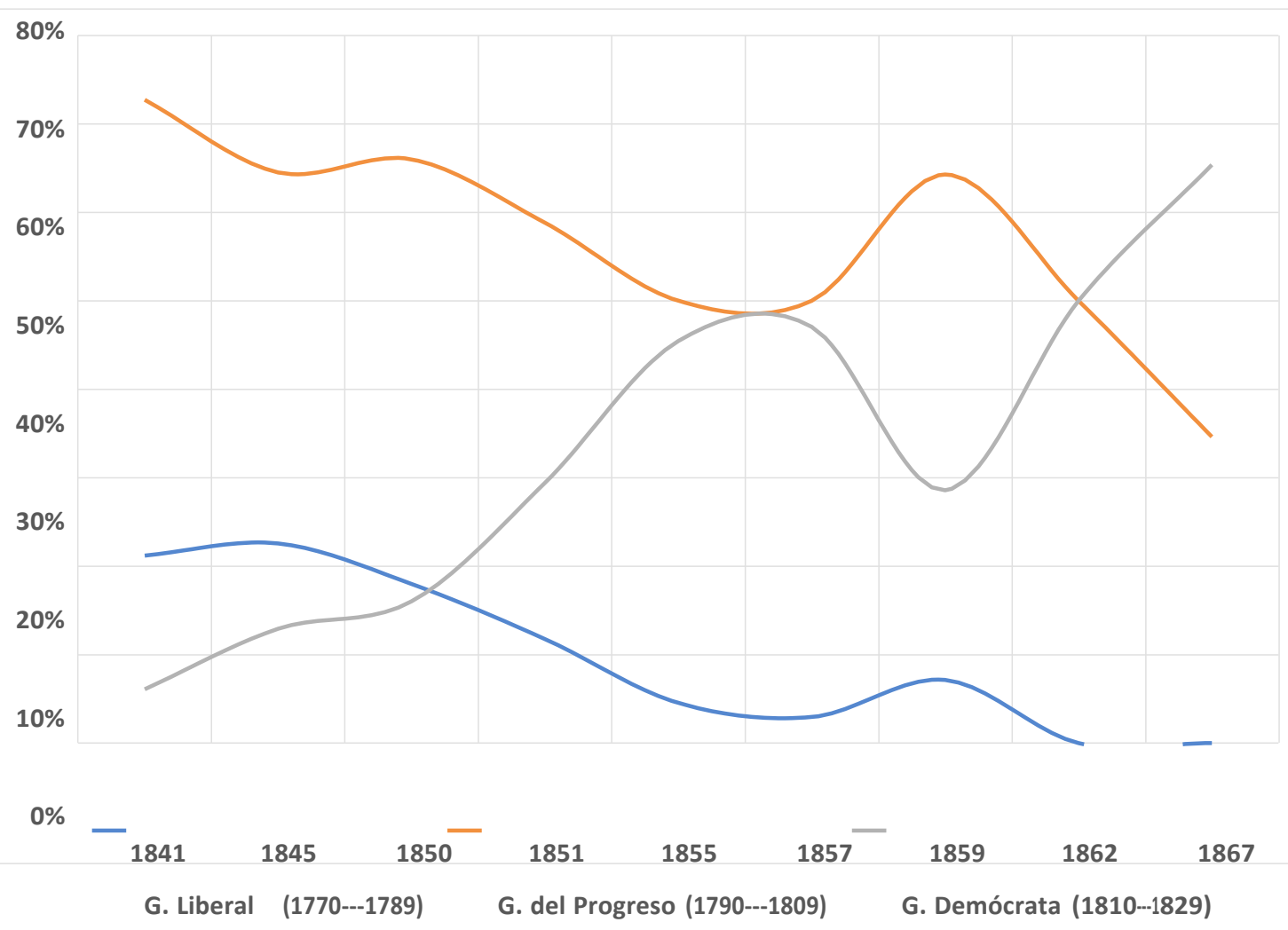

Fuente. Elaboración propia

Para determinar un perfil profesional de los miembros de los comités y jurados españoles, en función de las características de las instituciones de la que han formado parte, hemos establecido tres categorias: Instituciones de perfil artístico-cultural, de perfil científico-técnico, y de perfil jurídico-político. En la Tabla 2 se señalan detalladamente las instituciones que hemos agregado 
en cada categoria. En cada exposición el peso de cada grupo profesional (Figura 4) no varía sustancialmente, aunque en las universales, sobre todo desde la de París de 1855, se incrementó considerablemente la proporción de los que han formado parte de instituciones de perfil artístico y cultural.

El grupo de profesionales de instituciones de perfil científico-técnico son el grupo más numeroso, de media un $72 \%$ de los miembros de cada exposición, pero igualmente en promedio un $71 \%$ en cada exposición cuenta con un perfil jurídico-político.

Figura 4. Porcentaje por actividad profesional de los miembros de las comisiones españolas en las exposiciones nacionales y universals

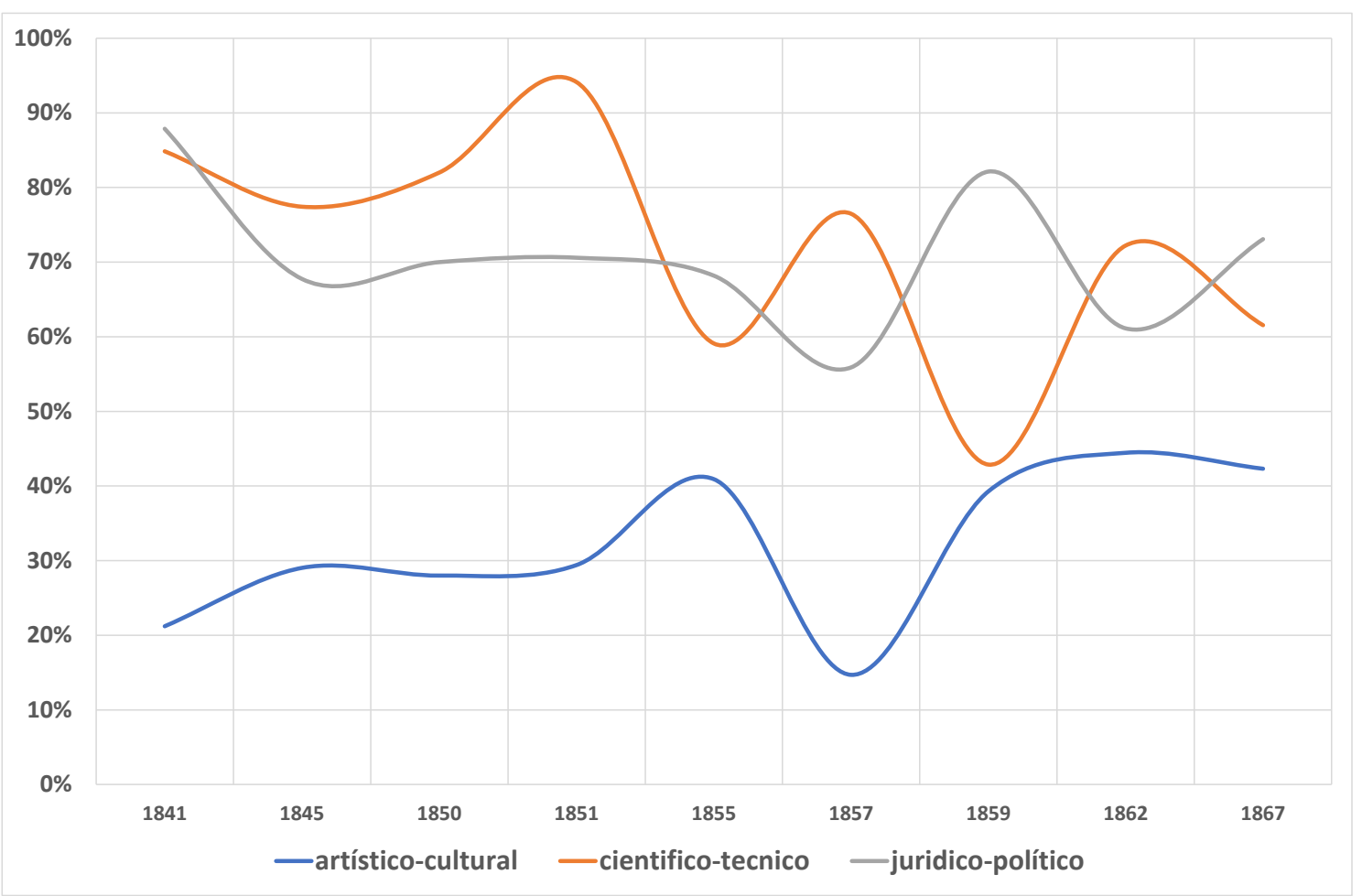

Fuente. Elaboración propia (cada persona puede contar con uno o más perfiles profesionales)

Los comités y jurados de las exposiciones económicas tienen un perfil científico-técnico y un marcado perfil jurídico-político, y junto a ello además una destacada posición gubernamental, en una proporción muy alta han sido ministros en el reinado de Isabel II o lo serán en el Sexenio y en la Restauración. De media han formado parte del gobierno un $23 \%$ de los miembros de los comités de cada exposición.

Los ministros que han formado parte de las comisiones españolas (Figura 6) tienen un perfil marcado profesional científico técnico, de media un $82 \%$, y en menor media un perfil artístico-cultura, de media un $52 \%$.

La orientación ideológica de los ministros que han formado parte de las comisiones españolas (Figura 5) esta equilibrada entre izquierda y derecha. Sin embargo, desde la primera exposición universal de París (1855) destaca que el número de ministros de orientación progresista sea mayor que el de los que han participado en gobiernos de orientación conservadora o moderada. 
Figura 5. Perfil profesional y orientación ideológica de los ministros que han formado parte de las comisiones españolas en la exposiciones nacionales y universals

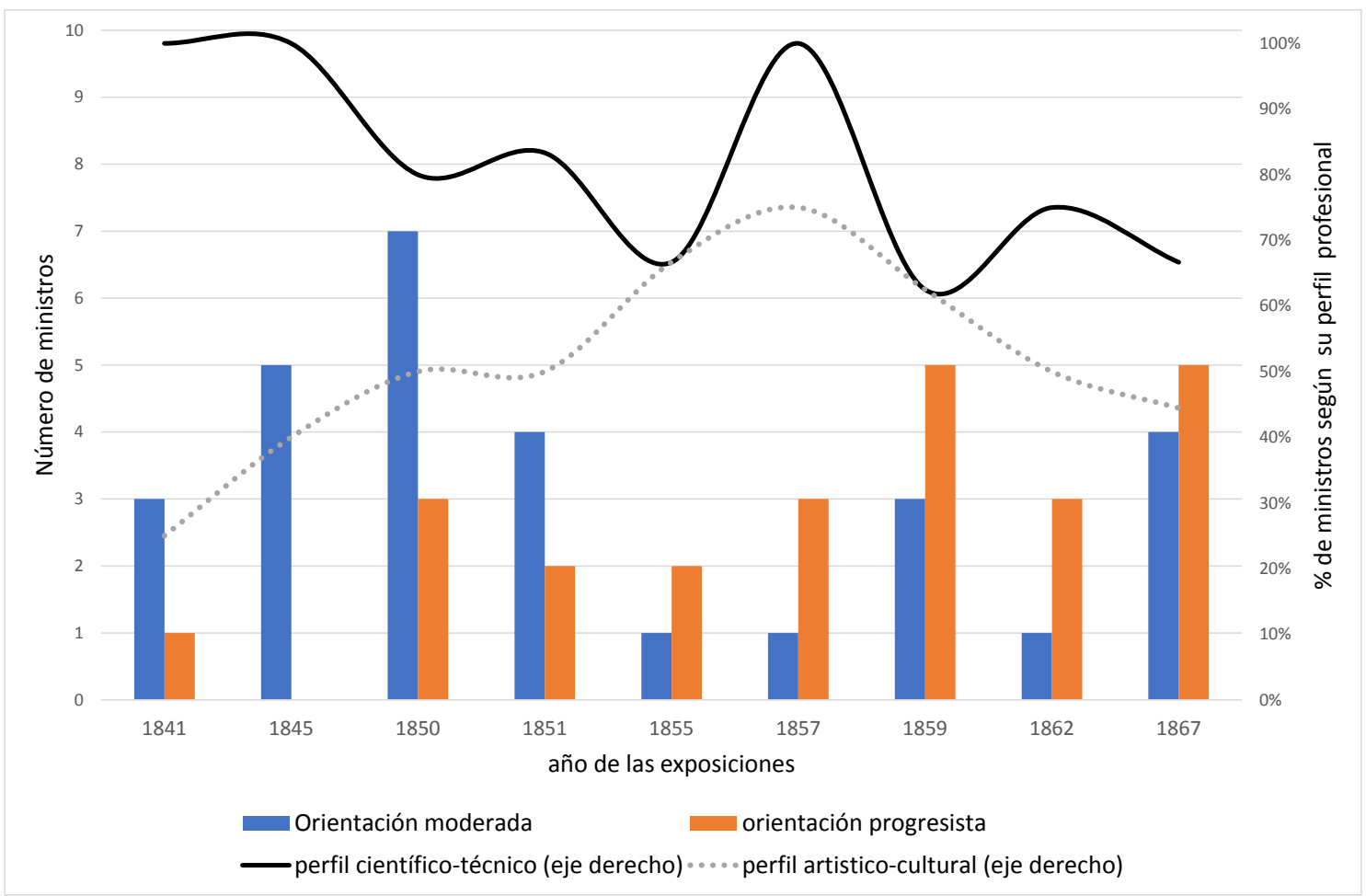

Fuente. Elaboración propia

\subsection{Continuidad y renovación}

La renovación de los miembros de los comités y jurados de las exposiciones económicas es alta, de media un $70 \%$ solo participó en una o dos exposiciones. Una proporción que al igual que la renovación generacional, se incrementó entre 1841 y 1867, pasando de un $70 \%$ a un $80 \%$ (Figura 6). Si atendemos a la continuidad, a los que han formado parte de tres o más exposiciones $^{23}$ (Figura 6), su número, tras incrementarse en las primeras exposiciones, disminuyó a partir de la universal de Londres de 1851.

${ }^{23}$ De mayor a menor número de exposiciones: José Caveda, Alejandro Oliván, Francisco de Luxán, Agustín Pascual, Joaquín José de Muro, Isaac Villanueva, Pedro Colón, Pascual Madoz, Manuel Fernández Durán, Alberto Felipe de Baldrich, Celestino del Piélago, Pascual Asensio, Diego Genaro, Francisco de Paula Orlando, Santiago Malacuera, Alejandro López, Joaquín Alfonso Martí, Ángel Riquelme, Manuel Garcia Barzanallana, Cipriano Segundo Montesinos, y Francisco de Paula Mellado. 
Figura 6. Miembros que participan más veces en las comisiones españolas en la exposiciones nacionales y universals

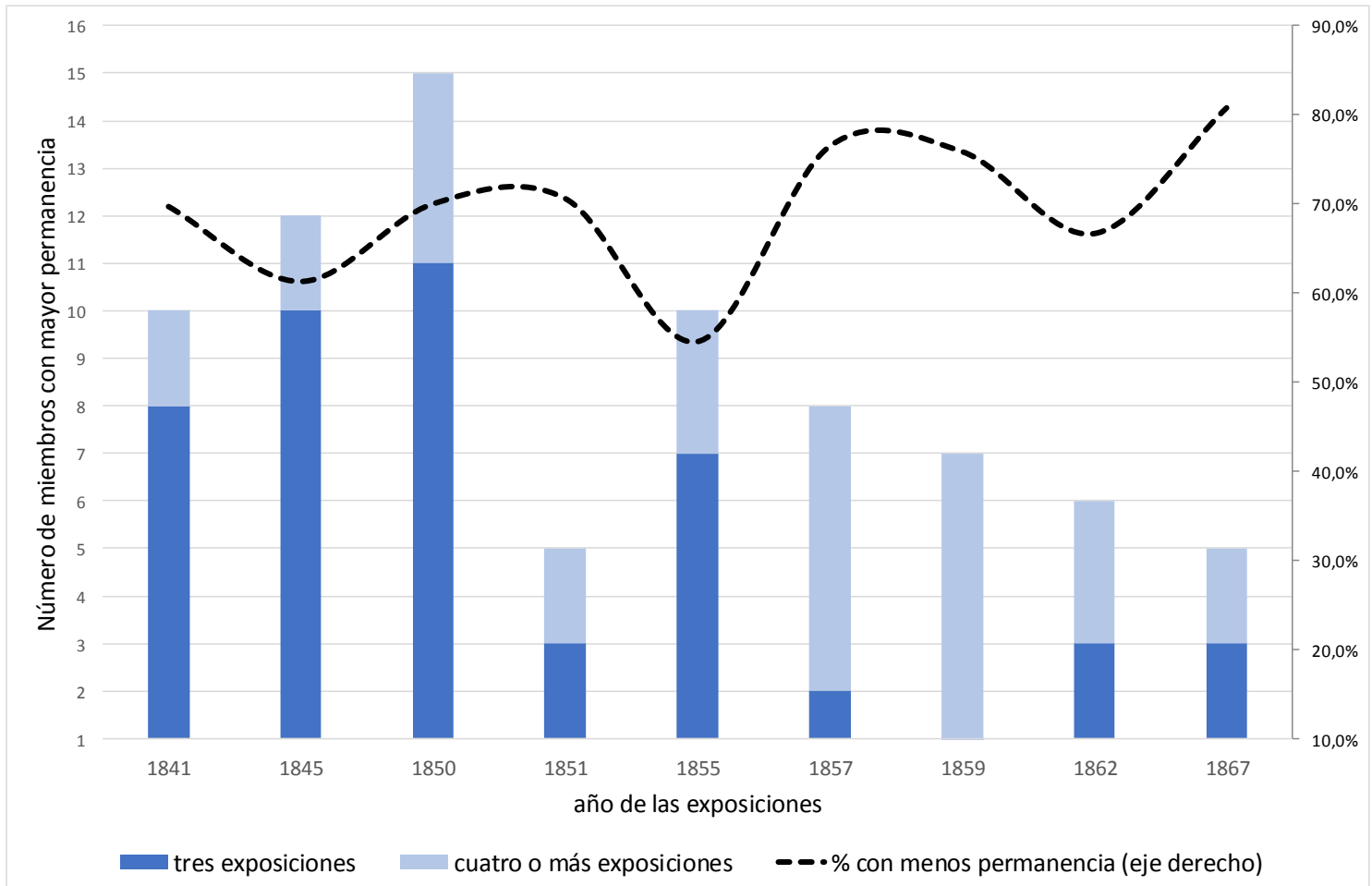

Fuente. Elaboración propia

Una visión más detallada, que se fijara exclusivamente en los que participaron en casi todas las exposiciones, en seis o más (Tabla 5), reduce la continuidad solo a tres: José Caveda, Alejandro Oliván, y Francisco de Luxán. Los tres pertenecen a la generación del progreso, nacidos alrededor de 1800, son destacados científicos, iniciadores en su disciplina, aunque en campos muy diferentes: Caveda ${ }^{24}$ en Humanidades (Lengua y literatura asturiana), Oliván en Ciencias Sociales y Jurídicas (Ciencias de la Administración ${ }^{25}$ ), y Luxán en Ciencias Naturales (Geologia26). Entre los tres encontramos todas las academias: Caveda es académico de la Española, de la de Bellas Artes y de la de Historia; Oliván es académico de la Española, de la de Bellas Artes, y de la de Ciencias Morales y Políticas; y Luxán es académico de la de Ciencias.

Tres relevantes académicos vinculados por su participación en las instituciones de innovación técnica; en la nueva administración liberal en el Ministerio de Fomento Luxán es ministro; Caveda director general; y Oliván consejero. En las agencias científicas y de innovación técnica los tres formaron parte de la Comisión de Estadística; Luxán y Oliván de la Comisión de pesos y medidas y de la Sociedad Matritense de Amigos del País; y Luxán además entre otras instituciones, forma

24 Sobre José Caveda puede verse la biografia de Etelvino González en el Diccionario biográfico de la Academia de la Historia (González López).

25 García de Enterría señaló que en España con la obra de Olivan surge la Ciencia de la Administración (Oliván, 1843), iniciación a la que Baena suma a Javier de Burgos y a Posada Herrera y que deslinda del Derecho Administrativo que toma cuerpo con Colmeiro (Baena del Alcázar, Curso de Ciencia de la Administración, 1985, págs. 56-57).

26 Sobre la dimensión científica de Luxán ver (Boixereu Vila, 2016) y sobre el papel de Luxán en la Comisión del Mapa Geológico. (Rábano Gutiérrez del Arroyo, 2015). 
parte del Mapa Geológico, del Observatorio astronómico, de la Academia de Artilleria, y de la Sociedad de Instrucción Pública.

Tres personalidades con un marcado perfil científico-técnico que mantuvieron posiciones ideológicas muy diferenciadas, Luxán es un dirigente del partido progresista, representa la herencia de los liberales de Cádiz, donde su padre fue un destacado diputado; Caveda, la linea de la ilustración, del pensamiento de Jovellanos; y Oliván se encuadra en el liberalismo doctrinario. Los tres tuvieron una destacada participación en las instituciones politicas del Estado liberal, fueron diputados y consejeros de Estado; y además Luxán y Oliván ministros y senadores.

Si nos fijáramos exclusivamente en las exposiciones universales, a este trio habria que añadir otros dos: un científico de enorme relevancia, Agustín Pascual $^{27}$ iniciador de la ciencia de montes (González-Doncel \& Gil, 2013, págs. 561-564), y un politico progresista de primer nivel, Pascual Madoz ${ }^{28}$. Ambos formaron parte de comité español en las universales de 1855, 1862 y 1867.

Tabla 5. Miembros de los comités y jurados españoles con mayor participación en las exposiciones económicas en el reinado de Isabel II

\begin{tabular}{|c|c|c|c|}
\hline \multicolumn{4}{|c|}{ Miembros de los comités y jurados que participan en seis o más exposiciones } \\
\hline & $\begin{array}{l}\text { José Caveda } \\
\text { y Nava } \\
(1796-1882) \\
\text { Lengua y literatura } \\
\text { asturiana }\end{array}$ & $\begin{array}{l}\text { Alejandro Oliván } \\
\text { y Borruel } \\
(1796-1878) \\
\text { Ciencias de la } \\
\text { administración }\end{array}$ & $\begin{array}{l}\text { Francisco de Luxán } \\
\text { Miguel-Romero } \\
(1799-1867) \\
\text { Geologia y } \\
\text { Metalurgia }\end{array}$ \\
\hline $\begin{array}{l}\text { Exposiciones } \\
\text { en las que } \\
\text { participan }\end{array}$ & $\begin{array}{l}\text { Expo. industrial de } \\
1845 \text { y } 1850 . \\
\text { Expo. agricultura } \\
1857 \\
\text { Proyecto Expo. } \\
\text { Hispanoamericana de } \\
1859 \\
\text { Expo. universal de } \\
1851,1855,1862 \text { y } \\
1867\end{array}$ & $\begin{array}{l}\text { Expo. agricultura } \\
1857 \\
\text { Proyecto Expo. } \\
\text { Hispanoamericana de } \\
1859 \\
\text { Expo. universal de } \\
1851,1855 \text { y } 1862\end{array}$ & $\begin{array}{l}\text { Expo. industrial de } \\
1841 \text { y } 1850 \\
\text { Expo. agricultura } \\
1857 \\
\text { Proyecto Expo. } \\
\text { Hispanoamericana de } \\
1859 \\
\text { Expo. universal de } \\
1862 \text { y } 1867\end{array}$ \\
\hline
\end{tabular}

27 Agustín Pascual González (1818-1884) "Introductor de la dasonomía en España, fundador de la Escuela de Ingenieros de Montes y renovador de la Administración Forestal" (Gil Sánchez, s.f.).

28 Sobre Pascual Madoz e Ibáñez (1805-1870), diputado, ministro, jurista, geógrafo, estadístico, y más allá de la desamortización, puede verse la biografia de Francisco Javier Paredes, Libertad y progreso en la monarquia isabelina (Paredes Alonso, 1991). 
LA GOBERNANZA DEL SISTEMA DE LAS EXPOSICIONES ECONÓMICAS...

\begin{tabular}{|c|c|c|c|}
\hline $\begin{array}{l}\text { Instituciones } \\
\text { de perfil } \\
\text { artistico- } \\
\text { cultural de } \\
\text { las que } \\
\text { forma parte }\end{array}$ & $\begin{array}{l}\text { Academia Española } \\
\text { Academia de Bellas } \\
\text { Artes } \\
\text { Academia de Historia } \\
\text { Museo Nacional de } \\
\text { Pinturas } \\
\text { Ateneo científico, } \\
\text { literario y artístico de } \\
\text { Madrid } \\
\text { Sociedad } \\
\text { Arqueológica } \\
\text { Matritense }\end{array}$ & $\begin{array}{l}\text { Academia Española } \\
\text { Academia de Bellas } \\
\text { Artes } \\
\text { Liceo Artístico y } \\
\text { Literario de Madrid } \\
\text { Ateneo científico, } \\
\text { literario y artístico de } \\
\text { Madrid }\end{array}$ & $\begin{array}{l}\text { Redacción de El } \\
\text { Espectador }\end{array}$ \\
\hline $\begin{array}{l}\text { Instituciones } \\
\text { de perfil } \\
\text { cientifico- } \\
\text { técnico de } \\
\text { las que } \\
\text { forma parte }\end{array}$ & $\begin{array}{l}\text { Comisión de } \\
\text { estadística general del } \\
\text { reino. }\end{array}$ & $\begin{array}{l}\text { Academia de Ciencias } \\
\text { Morales y Políticas } \\
\text { Comisión de } \\
\text { estadística general del } \\
\text { reino. } \\
\text { Comisión de pesas y } \\
\text { medidas } \\
\text { Sociedad Económica } \\
\text { Matritense. }\end{array}$ & $\begin{array}{l}\text { Academia de Ciencias } \\
\text { Naturales } \\
\text { Academia de Ciencias } \\
\text { Exactas, Físicas y } \\
\text { Naturales } \\
\text { Comisión del mapa } \\
\text { geológico } \\
\text { Observatorio } \\
\text { astronómico } \\
\text { Comisión de } \\
\text { estadística general del } \\
\text { reino. } \\
\text { Comisión de pesas y } \\
\text { medidas } \\
\text { Academia de Artilleria } \\
\text { Instituto de } \\
\text { Ingenieros Civiles } \\
\text { Sociedad Económica } \\
\text { Matritense } \\
\text { Sociedad de } \\
\text { Instrucción Pública } \\
\text { Sociedad El Porvenir } \\
\text { Sociedad de la } \\
\text { Lengua Universal }\end{array}$ \\
\hline
\end{tabular}




\begin{tabular}{|c|c|c|c|}
\hline $\begin{array}{l}\text { Instituciones } \\
\text { de perfil } \\
\text { juridico- } \\
\text { politico de } \\
\text { las que } \\
\text { forma parte }\end{array}$ & $\begin{array}{l}\text { Junta del Principado } \\
\text { de Asturias } \\
\text { Diputado } \\
\text { Director general de } \\
\text { Instrucción } \\
\text { Director de } \\
\text { Administración } \\
\text { General } \\
\text { Director general de } \\
\text { agricultura, industria } \\
\text { y comercio } \\
\text { Consejo Real } \\
\text { Consejo de } \\
\text { Agricultura, Industria } \\
\text { y Comercio }\end{array}$ & $\begin{array}{l}\text { Diputado } \\
\text { Senador } \\
\text { Ministro de Marina y } \\
\text { Gobernación de } \\
\text { Ultramar } \\
\text { Consejo Real } \\
\text { Consejo de } \\
\text { Agricultura, Industria } \\
\text { y Comercio }\end{array}$ & $\begin{array}{l}\text { Diputado } \\
\text { Senador } \\
\text { Consejo de Estado } \\
\text { Ministro de Fomento } \\
\text { Consejo de } \\
\text { Instrucción Pública }\end{array}$ \\
\hline
\end{tabular}

Fuente. Elaboración propia

\section{CONCLUSIONES}

Entre 1833 y 1868 España adoptó una política orientada a favorecer el desarrollo técnico-industrial. Un proyecto para la sociedad industrial en el que las exposiciones de fomento de la economía tuvieron especial relevancia, una línea política transversal, impulsada desde la centralidad politica en la que los progresistas tuvieron un papel decisivo. Una orientación estratégica en la que destaca la intensidad de la acción gubernamental durante las exposiciones universales de Paris (1855 y 1867) y también durante la Exposición agrícola de Madrid de 1857. En la primera de Paris, el gobierno presidido por Espartero, con el ministro de Fomento, Francisco de Luxán, un científico y político progresista, subrayó el alcance transversal de esta política. En la Agrícola de Madrid el reconocimiento de la labor de Luxán por el gobierno de O`Donnell ayudó a confirmar la centralidad del proyecto. Junto al Ministerio de Fomento los gobiernos provinciales y su red de medios de comunicación, los Boletines oficiales de cada provincia, participaron intensamente en la extensión de esta política.

Si se subraya la continuidad institucional y al tiempo se destaca la novedad de las exposiciones universales, se puede afirmar que en las décadas centrales del XIX se articuló un modelo de gobernanza multinivel, y multisectorial, local y global, de exposiciones generalistas y especializadas, en el que Estado y Sociedad civil, desarrollan un espacio de colaboración público privado, un modelo de administración participada, que se constituye para cada exposición. Un modelo institucional que se apoya en una red de comunicaciones en la que el ferrocarril, el telégrafo, y desde luego los periódicos son también un nuevo y destacado exponente de la sociedad industrial. 
A partir de 1840, tras el fin de la guerra civil, en la Regencia de Espartero, la generación del progreso se incorporó a la dirección de las exposiciones económicas, un grupo que cuenta con un nuevo perfil científico-técnico y que desarrolló un papel destacado en la política. La renovación en cada exposición de una parte muy importante de los miembros de los comités y jurados convive con la continuidad de un núcleo reducido, José Caveda, Alejandro Oliván, y Francisco de Luxán, nacidos en torno al ochocientos, con un perfil científico-técnico muy destacado, y que desde una orientación ideológica contrapuesta desarrollaron un papel político muy relevante.

Los ciudadanos lo son ya del globo, anticipa Luxán en 1837; y treinta años después, en 1867 podrán comprobarlo en París, los quince millones de visitantes de la Exposición, y al mismo tiempo en España podrán corrobóralo los lectores de los diarios y de la nueva prensa gráfica.

\section{V.REFERENCIAS}

Baena del Alcázar, M. (1985). Curso de Ciencia de la Administración. Madrid: Tecnos.

Baena del Alcázar, M. (2012). Origen y consolidación de la Administración Liberal Española (1838-1900) Los órganos centrales. Madrid: Instituto Nacional de Administración Pública.

Boixereu Vila, E. (2016). La dimensión científica del geólogo Francisco de Luxán. En Milicia y Geología. Francisco de Luxán (págs. 60-71). Madrid: Ministerio de Defensa y Ministerio de Economía y Competitividad.

Burgeño, J. (1996). Geografía politica de la España constitucional. División provincial. Madrid: Centro de Estudios Constitucionales.

Capel Sáez, H. (2007). Las exposiciones nacionales y locales en la España del siglo XIX. En M. Silva Suarez (Ed.), Técnica e ingenieria en España. IV. El Ochocientos.Pensamiento, profesiones y sociedad (págs. 151-213). Zaragoza: Institución Fernando el Católico.

Castells, M. (2005). La era de la información. Vol I. La sociedad Red. Madrid: Alianza editorial ( $1^{\text {a }}$ edicicón 1997).

Cuenca Toribio, J. (2020). Antonio Aguilar Ochoa y Correa. Obtenido de Diccionario Biográfico de Real Academia de la Historia: http: / / dbe.rah.es/biografias / 5358/antonio-aguilar-ochoa-y-correa

Cuenca Toribio, J. (s.f.). Manuel Orovio y Echagüe. Recuperado el 2020, de http://dbe.rah.es/biografias/7348/manuel-orovio-y-echague

Esteve Serrano, A. (1982). Estudios de teoría ortográfica del Español. Universidad de Murcia.

Florez Estrada, A. (1811). Examen imparcial de las disensiones de la américa con España, de los medios de su reconciliación y de la prosperidad de todas las naciones. Cádiz (2 $\left.{ }^{\mathrm{a}} 1812\right)$ : Imprenta de Manuel Ximénez Carreño.

Gil Sánchez, L. (s.f.). Diccionario Biográfico electrónico (DB e) . (R. A. Historia, Editor) Recuperado el 2020, de http:/ /dbe.rah.es/

Gomá, J. (2003). Imitación y experiencia. Barcelona (2005): Crítica.

González López, E. (s.f.). José Caveda Nava. Recuperado el 2020, de Diccionario Biográfico electrónico (DB e): http:/ / dbe.rah.es /

González-Doncel, I., \& Gil, L. (2013). Dasonomía y práctica forestal. En M. Silva Suárez (Ed.), Técnica e Ingeniería en España VII. El Ochocientos. De las profundidades a las alturas (págs. 559-602). Zaragoza: Real Academia de 
Ingeniería. Institución Fernando El Católico. Prensas de la Universidad de Zaragoza.

Hernández Socorro , M. (1996). Manuel Ponce de León y Falcón. Pintor Gran Canario. Las Palmas de Gran Canaria: Real Sociedad Económica de Amigos del País de Gran Canaria.

Hernández Socorro, M. (2009). Nuevas formas. Nuevas aportaciones. Los pintores canarios en la encrucijada del siglo XIX. En M. Hernandez Socorro, G. Fuentes Pérez, \& C. Gaviño de Franchy, El despertar de la cultura en la época contemporánea. Artistas y manifestaciones culturales del siglo XIX en Canarias. Santa Cruz de Tenerife ; Las Palmas de Gran Canaria: Gobierno de Canarias, Viceconsejería de Cultura y Deportes.

Junta de calificación de la exposición. (1842). Memoria de la Junta de Calificación de los productos de la Industria española presentados en la Exposición pública de 1841. Madrid: Imprenta de D. Miguel de Burgos.

Junta de Comercio de Barcelona. (1844). Esposición pública de productos de la industria española. Barcelona: Imprenta de J. Tauló.

Junta directiva de la exposición de 1862. (1864). Memoria histórica y oficial de la exposición provincial de Canarias de Agricultura, Industria y Artes de 1862. Imprenta de Tomas B. Mateos.

Lasheras Peña, A. B. (2009). España en Paris. La imagen nacional en las exposiciones universales 1855-1900. Santander: Universidad de Cantabria.

Luxán Meléndez, J. (2016). Una politica para la ciencia en el reinado de Isabel II. Madrid: Centro de Estudios Políticos y Constitucionales.

Luxán Meléndez, S. (2006). La opción agricola e industrial del tabaco en Canarias. Una perspectiva institucional : los origenes 1827-1936. Las Palmas de Gran Canaria: Universidad de las Palmas de Gran Canaria y Sociedad Canaria de Fomento Económico S. A. (PROEXCA), Consejería de Economía y Hacienda del Gobierno de Canarias.

Luxán Miguel-Romero, F. (1837). Itinerario de un viaje facultativo verificado en el continente $y$ en Inglaterra. Madrid: Imprenta de Don Eusebio Aguado.

Luxán Miguel-Romero, F. (13 de junio de 1842). Discurso en la entrega de premios de la exposición universal de 1841, celebrada ante el Regente el 12 de junio de 1842. El Espectador.

Luxán Miguel-Romero, F. (1863). Memoria de la Exposición Internacional de Londres de 1862. Madrid: Imprenta Nacional.

Montesino, C. (1863). Memoria de la exposición internacional de Londres de 1862 : clase $V$, material de ferrocarriles. Madrid: Imprenta Nacional.

Oliván, A. (1843). De la Administración Pública con relación a España. Madrid (1954): Instituto de Estudios Políticos (prólogo de Eduardo García de Enterria).

Orellana, F. (1860). Reseña de la Exposición Industrial y Artistica de productos del principado de Cataluña. Establecimiento Tipográfico de Jaime Jesús.

Pardo Redondo, G. (2017). El Crystal Palace de Nueva York y su contribución en la historia de las construcciones metálicas (Tesis doctoral). Universidad Politécnica de Valencia.

Paredes Alonso, F. J. (1991). Pascual Madoz 1805-1870. Libertad y progreso en la monarquia isabelina. Pamplona: EUNSA.

Pérez Juan, J. A. (2008). EL MINISTERIO DE COMERCIO, INSTRUCCIÓN y Obras Públicas (1847-1851). Madrid: Universidad de Elche e Instituto nacional de Administración Pública. 
Quintanilla, M. (2005). Tecnologia: un enfoque fiolosófico y otros ensayos de filosofía de la tecnología. México D.F.: Fondo de Cultura Económica.

Rábano Gutiérrez del Arroyo, I. (2015). Los Cimientos de la Geología. La Comisión del Mapa Geológico de España (1849-1910). Madrid: Instituto Geológico y Minero de España.

Ramón Teijelo, P. J., \& Silva Suárez, M. (2007). El Real Conservatorio de Artes (1824-1887), cuerpo facultativo y consultivo auxiliar en el ramo de la industria. En M. Silva Suárez (Ed.), Técnica e ingeniería en España $V E l$ Ochocientos Profesiones e instituciones civiles (págs. 235-294). Zaragoza: Real Academia de Ingeniería. Institución Fernando el Católico.

Sánchez Romero , M. (2009). La Industria Valenciana en torno a la Exposición Regional de 1909. (Tesis doctoral). Universidad Politécnica de Valencia.

Silva Suárez, M. (2013). De las alturas... y de otras muchas cosas además. Presentación. En Técina e Ingeniería en España. Tomo VII El Ochocientos De las profundidades a las alturas (págs. 8-103). Zaragoza: Real Academia de Ingeniería. Institución Fernando El Católico. Prensas Universitarias de Zaragoza.

Trena, J. (1971). Fermín Arteta. Ministro de Isabel II (la anticipación de un tecnócrata). Madrid: Fundación Juan March y Guadarrama.

Urquijo Goitia, J. R. (2001). Gobiernos y Ministros Españoles en la Edad Contempóranea (1808-2000). Madrid (2008): Consejo Superior de Investigaciones Científicas.

Vallés, J. (2020). Ciencia politica. Un manual. Barcelona (1ª 2000): Ariel.

Viera, M. (2020). El imaginario español en las Exposiciones Universales del siglo XIX. Exotismo y modernidad. Madrid: Cátedra.

Fecha de envio / Submission date: 31/12/2020

Fecha de aceptación / Acceptance date: 06/02/2021 